\title{
Microstress cycle and contact fatigue of spiral bevel gears by rolling-sliding of asperity contact
}

\author{
Wei CAO ${ }^{1}$, Si REN ${ }^{2}$, Wei PU ${ }^{2,3, *}$, Ke XIAO ${ }^{4}$ \\ ${ }^{1}$ School of Construction Machinery, Chang'an University, Xi'an 710064, China \\ ${ }^{2}$ School of Aeronautics and Astronautics, Sichuan University, Chengdu 610065, China \\ ${ }^{3}$ Department of Mechanical Engineering, Massachusetts Institute of Technology, Cambridge, Massachusetts 02139, USA \\ ${ }^{4}$ College of Mechanical Engineering, Chongqing University, Chongqing 400044, China \\ Received: 07 July 2019 / Revised: 27 September 2019 / Accepted: 17 October 2019 \\ (C) The author(s) 2019.
}

\begin{abstract}
The rolling contact fatigue (RCF) model is commonly used to predict the contact fatigue life when the sliding is insignificant in contact surfaces. However, many studies reveal that the sliding, compared to the rolling state, can lead to a considerable reduction of the fatigue life and an excessive increase of the pitting area, which result from the microscopic stress cycle growth caused by the sliding of the asperity contact. This suggests that fatigue life in the rolling-sliding condition can be overestimated based only on the RCF model. The rubbing surfaces of spiral bevel gears are subject to typical rolling-sliding motion. This paper aims to study the mechanism of the micro stress cycle along the meshing path and provide a reasonable method for predicting the fatigue life in spiral bevel gears. The microscopic stress cycle equation is derived with the consideration of gear meshing parameters. The combination of the RCF model and asperity stress cycle is developed to calculate the fatigue life in spiral bevel gears. We find that the contact fatigue life decreases significantly compared with that obtained from the RCF model. There is strong evidence that the microscopic stress cycle is remarkably increased by the rolling-sliding motion of the asperity contact, which is consistent with the experimental data in previous literature. In addition, the fatigue life under different assembling misalignments are investigated and the results demonstrate the important role of misalignments on fatigue life.
\end{abstract}

Keywords: rolling/sliding contact fatigue; stress cycle; spiral bevel gear; mixed elasto-hydrodynamic lubrication; assembling misalignment

\section{Introduction}

Surface pitting is a major form of primary failure for mechanical components, such as roller element bearings, wheel rails, and various types of gears. When the components periodically suffer high contact stresses, cracks may initiate near the surface and then propagate towards the surface to form a surface spall or pit, although the components are properly assembled, loaded, and lubricated [1].

Rolling contact fatigue (RCF) theories have been widely used in roller element bearings, rail-wheel contacts, and spur gears [1], when the sliding velocity between two surfaces is insignificant. In fact, a considerable sliding can be found in the cross-axis gear transmission, especially for spiral bevel and hypoid gears. The two-disc experiments have demonstrated that the relative sliding may result in a great impact on fatigue life, and quantitatively, the increasing of the sliding ratio from $0 \%$ to $10 \%$ leads to a reduction of fatigue life by two orders of magnitude, as reported in the earlier study of Bujold et al. [2]. It is evident that the engineering machined surface is not ideally smooth, which may complicate the surface contact. Under the

* Corresponding author: Wei PU, E-mail: Pwei@scu.edu.cn 
pure rolling contact, the number of surface stress cycles on a certain piece of material is equal to the rolling cycles. With the presence of the relative sliding between two mating surfaces, the stress cycles may be considerably high because one of the surfaces is inevitably experiencing the many asperities of another surface over the contact zone. Most recently, the significant influence of sliding on fatigue life has been revealed by Ramalho et al. [3], Lee et al. [4], Seo et al. [5], and Oksanen et al. [6] experimentally, and $\mathrm{Pu}$ et al. [7] theoretically. Therefore, conventional RCF theories tend to overestimate the fatigue life of spiral bevel gears as the sliding between the conjugated gear flanks is not considered [8].

A famous RCF model for rolling-element bearings was proposed by Lundberg and Palmgren [9] by relating the probability of failure to the number of stress cycles based on the statistical theory developed by Weibull [10]. The Lundberg-Palmgren [9] model has a few limitations, which include overlooking the presence of the lubricant film and surface shear traction. In order to overcome these limitations, Ioannides and Harris [11], Zaretsky [12], and Tallian [13] improved and extended the Lundberg-Palmgren model for a wider range of applications. Although the aforementioned models considered the non-conformal bodies to have smooth surfaces or took the roughness into account using stochastic parameters, their findings have greatly encouraged further modifications. More specifically, the models proposed by Ioannides and Harris [11] and Zaretsky [12] can predict the RCF life through the integration of infinitesimal volumetric elements stress and appear to be suitable for a microscale stress consideration under the asperity contact. Then, the roughness was involved in the fatigue analysis in Refs. [14] and [15], and the results showed that the surface roughness can increase the effective stress, leading to the reduction of fatigue life. Similar methods can be found in Ref. [16] to study the effect of the rootmean-square (RMS) roughness on the line-contact fatigue life. Previous reports indicated that the reduction of RMS roughness from 0.95 to $0.15 \mu \mathrm{m}$ can improve the fatigue life by $85 \%$. Additionally, Zhu et al. [17] also applied the model proposed by Zaretsky [12] for spur gear pitting analysis by considering the real three dimensional (3D) roughness under the mixed lubrication, and the predicted pitting life was in close agreement with the test data.

Pitting fatigue is closely related to stress distributions. If the contact surface is sufficiently fine-machined, the surface roughness can be neglected. Similar assumptions have been applied in Refs. [9, 11-13], where the stressed material volumes were calculated by the pure Hertzian contact. Due to the presence of machined rough surfaces, it is necessary to determine the detailed pressure distribution in the mixed lubrication, as the localized pressure peaks may be significantly higher than the Hertzian pressure, which can cause concentrations of subsurface stress and lead to a reduction of the pitting life of components. Scholars have made great efforts to develop the mixed elasto-hydrodynamic lubrication (EHL) model with the consideration of roughness. Representative achievements were made by Xu and Sadeghi [18], Zhu and Ai [19], Jiang et al. [20], Sicuteri and Salant [21], Hu and Zhu [22], Holmes et al. [23], Bayada et al. [24], Zhu et al. [25, 26], et al. The developed mixed EHL model has been implemented in the subsurface stress-based fatigue-life model proposed by Zaretsky [12] as an effective approach for pitting fatigue analysis, as reported by Ai [15], Epstein et al. [16], Zhu et al. [17], Greco et al. [27], and Pu et al. [7]. Similar combinations of fatigue model and mixed EHL were also applied by Li and Kahraman [28], Li and Anisetti [29], et al. Modifications to the mixed EHL model have been attempted in Refs. [30] and [31] to simulate the mixed EHL elliptical contacts with arbitrary velocity vectors by considering the effect of $3 \mathrm{D}$ roughness. These modified models laid the foundation for the later lubrication analysis in spiral bevel gears and hypoid gears by $\mathrm{Pu}$ et al. [32] and Cao et al. [8].

According to the above literature review, the RCF of rolling element bearing and spur gears have been investigated extensively in recent years. However, due to the complex contact geometry, relevant studies on spiral bevel gears are limited. Theoretical simulations by finite element method on the fatigue crack growth in spiral bevel gears can be found in Refs. [33, 34]. Experiments were reported by Asi [35] and $\mathrm{Xi}$ and Wang [36] regarding the bending fatigue failure and surface contact fatigue failure of hypoid gears. Based on the model proposed by Zaretsky [12], Cao et al. [8] 
studied the contact fatigue of spiral bevel gears under different contact paths, but the increased stress cycles due to the sliding asperity contact were ignored.

The present study is aimed to propose a pitting life prediction approach for spiral bevel gears considering the real 3D surface roughness, as the sliding asperity contacts in conjugated surfaces may cause high asperity contact pressure and significantly increase stress cycles. In order to conduct the mixed EHL analysis for spiral bevel gears, the tooth contact analysis (TCA) model is needed to obtain the contact geometry, velocity vectors, and meshing loads $[8,37]$. The surface roughness of spiral bevel gears, generated by a certain machining process, e.g., grinding, is measured by an optical profiler, showing a general sinusoid-like geometry as reported in Ref. [38]. Therefore, the sinusoid-like roughness is used to fit the roughness profile in the present study to develop the equation for counting the microstress cycle under the rolling-sliding contact in spiral bevel gears. Based on the coupling of the TCA model, mixed EHL model, and fatigue model, the contact stress and fatigue life, subjected to different assembling errors, are investigated numerically.

\section{Equations of meshing considering assembling errors}

The first step of the mixed EHL lubrication and fatigue analysis is to determine the assembling positions with position errors. It is important to clarify that the contact geometry, contact paths, and meshing load in spiral bevel gears are relevant to the position errors. Figure 1 plots the 3D assembling relationship between the pinion and gear, including the presence of misalignments. Unit vectors $\mathbf{p}_{\mathrm{p}}$ and $\mathbf{p}_{\mathrm{g}}$ mark the axis of pinion and gear, and their relative angular position is called the shaft angle $\sigma$, the offset direction is defined as $\mathbf{e}_{\mathrm{d}}=\mathbf{p}_{\mathrm{p}} \times \mathbf{p}_{\mathrm{g}}$. Symbols $\Delta H, \Delta J, \Delta E$, and $\Delta \sigma$ represent the pinion axial error, gear axial error, offset error, and shaft angle error, respectively. Points $O_{\mathrm{p}}$ and $O_{\mathrm{g}}$ are the design points of the intersection between the pinion axis and gear axis, as fixed with the pinion and gear axis, respectively. Points $Q_{\mathrm{p}}$ and $Q_{\mathrm{g}}$ are the images of points $O_{\mathrm{p}}$ and $O_{\mathrm{g}}$ as a result of the position errors $\Delta H$ and $\Delta J$. With zero position errors, point $O_{p}$ coincides with point $O_{g}$. The meshing of spiral bevel gears indicates that the driving surface is conjugated to the driven surface. Consequently, position vectors $\mathbf{R}_{\mathrm{bp}}$ and $\mathbf{R}_{\mathrm{bg}}$ are used to describe the contact of pinion and gear surfaces mathematically. It is worth mentioning that position vectors $\mathbf{R}_{\mathrm{bp}}$ and $\mathbf{R}_{\mathrm{bg}}$ are expressed in coordinates $\sum_{\mathrm{p}}=\left\{O_{\mathrm{p}}, \mathbf{e}_{\mathrm{d}} \times \mathbf{p}_{\mathrm{p}}, \mathbf{e}_{\mathrm{d}}, \mathbf{p}_{\mathrm{p}}\right\}$ and $\Sigma_{g}=\left\{O_{g}, \mathbf{e}_{d} \times \mathbf{p}_{g}, \mathbf{e}_{\mathrm{d}}, \mathbf{p}_{\mathrm{g}}\right\}$, which are fixed with the pinion and gear at points $O_{p}$ and $O_{g}$, as depicted in Fig. 1. According to the conjugate surface theory, the conjugation of the gear and pinion must satisfy the following three conditions $[39,40]$ :

(a) The unit normal vector of the pinion surface $\mathbf{n}_{\mathrm{p}}$ must be collinear with the unit normal vector of the gear surface $\mathbf{n}_{\mathrm{g}}$.

(b) Two surfaces can coincide at a certain point $M_{\mathrm{p}}$.

(c) The normal vector of the local contact $\left(\mathbf{n}_{\mathrm{p}}\right.$ and $\mathbf{n}_{\mathrm{g}}$ ) is orthogonal with the relative velocity.

For the convenience of vector operations, the vectors in system $\sum_{\mathrm{p}}$ are shifted to system $\sum_{\mathrm{g}}$ :

$$
\left(\begin{array}{l}
\mathbf{R}_{\mathrm{bp}}^{(\mathrm{g})} \\
\mathbf{n}_{\mathrm{p}}^{(\mathrm{g})} \\
\mathbf{p}_{\mathrm{p}}^{(\mathrm{g})}
\end{array}\right)=\mathbf{M}(\sigma+\Delta \sigma)\left(\begin{array}{l}
\mathbf{R}_{\mathrm{bp}} \\
\mathbf{n}_{\mathrm{p}} \\
\mathbf{p}_{\mathrm{p}}
\end{array}\right)
$$

where $\mathbf{M}(\sigma+\Delta \sigma)$ denotes the transformation matrix from system $\sum_{\mathrm{p}}$ to $\sum_{\mathrm{g}}$, which is expressed as

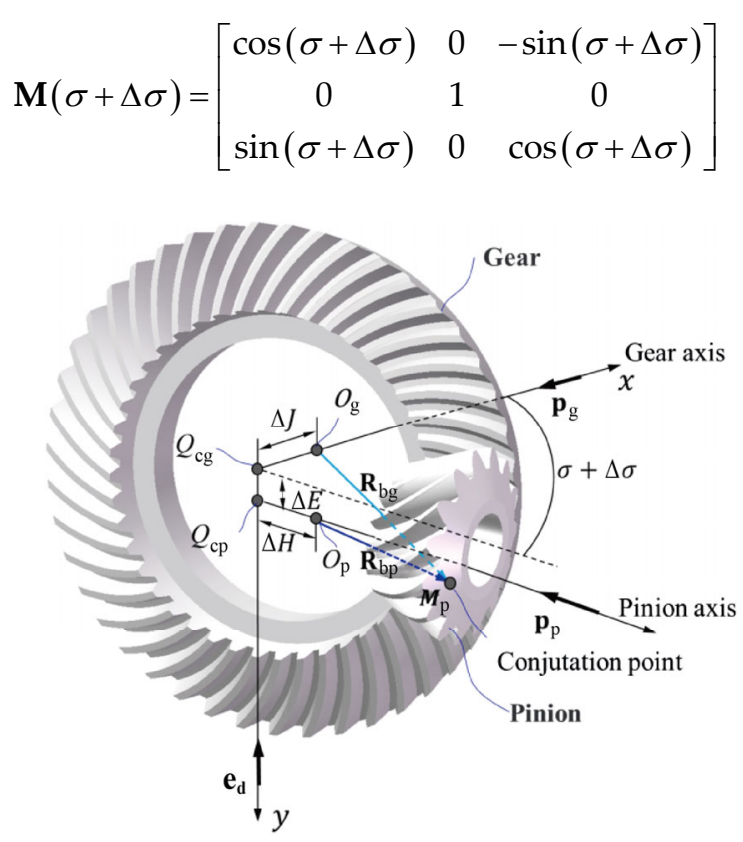

Fig. 1 Assembling position between the pinion and gear. 
To satisfy Condition (a), the pinion and gear need to rotate about their axes with angles $\phi_{\mathrm{p}}$ and $\phi_{\mathrm{g}}$, respectively, which can be mathematically described as

$$
\begin{aligned}
\mathbf{n}_{\mathrm{p}}^{(\phi)}= & \left(\mathbf{n}_{\mathrm{p}}^{(\mathrm{g})} \times \mathbf{p}_{\mathrm{p}}^{(\mathrm{g})}\right) \times \mathbf{p}_{\mathrm{p}}^{(\mathrm{g})}+\left(\mathbf{p}_{\mathrm{p}}^{(\mathrm{g})} \times \mathbf{n}_{\mathrm{p}}^{(\mathrm{g})}\right) \\
& \times \mathbf{p}_{\mathrm{p}}^{(\mathrm{g})} \cos \phi_{\mathrm{p}}+\left(\mathbf{p}_{\mathrm{p}}^{(\mathrm{g})} \times \mathbf{n}_{\mathrm{p}}^{(\mathrm{g})}\right) \sin \phi_{\mathrm{p}} \\
\mathbf{n}_{\mathrm{g}}^{(\phi)}= & \left(\mathbf{n}_{\mathrm{g}} \times \mathbf{p}_{\mathrm{g}}\right) \times \mathbf{p}_{\mathrm{g}}+\left(\mathbf{p}_{\mathrm{g}} \times \mathbf{n}_{\mathrm{g}}\right) \times \mathbf{p}_{\mathrm{g}} \cos \phi_{\mathrm{g}} \\
& +\left(\mathbf{p}_{\mathrm{g}} \times \mathbf{n}_{\mathrm{g}}\right) \sin \phi_{\mathrm{g}}
\end{aligned}
$$

It is assumed that normal vectors coincide each other after the rotations, i.e., $\mathbf{n}_{\mathrm{p}}^{(\phi)}=\mathbf{n}_{\mathrm{g}}^{(\phi)}$, then the rotational angles $\phi_{\mathrm{p}}$ and $\phi_{\mathrm{g}}$ can be solved explicitly as

$$
\begin{aligned}
& \phi_{\mathrm{p}}=\sin ^{-1}\left[\frac{\left(\mathbf{p}_{\mathrm{g}} \times \mathbf{p}_{\mathrm{p}}^{(\mathrm{g})}\right)\left(\mathbf{n}_{\mathrm{p}}^{(\mathrm{g})} \times \mathbf{p}_{\mathrm{p}}^{(\mathrm{g})}\right)-\mathbf{p}_{\mathrm{g}} \times \mathbf{n}_{\mathrm{g}}}{\left(\mathbf{p}_{\mathrm{p}}^{(\mathrm{g})} \times \mathbf{p}_{\mathrm{g}}\right) \times \mathbf{n}_{\mathrm{g}}} \cos \phi_{\mathrm{p} 0}\right] \\
& \phi_{\mathrm{g}}=\sin ^{-1}\left[\frac{\left(\mathbf{p}_{\mathrm{p}}^{(\mathrm{g})} \times \mathbf{p}_{\mathrm{g}}\right)\left(\mathbf{n}_{\mathrm{g}} \times \mathbf{p}_{\mathrm{g}}\right)-\mathbf{p}_{\mathrm{p}}^{(\mathrm{g})} \times \mathbf{n}_{\mathrm{p}}^{(\mathrm{g})}}{\left(\mathbf{p}_{\mathrm{g}} \times \mathbf{p}_{\mathrm{p}}^{(\mathrm{g})}\right) \times \mathbf{n}_{\mathrm{g}}} \cos \phi_{\mathrm{g} 0}\right]
\end{aligned}
$$

where

$$
\begin{gathered}
\phi_{\mathrm{p} 0}=\frac{\left(\mathbf{p}_{\mathrm{g}} \times \mathbf{p}_{\mathrm{p}}^{(\mathrm{g})}\right)\left(\mathbf{n}_{\mathrm{p}}^{(\mathrm{g})} \times \mathbf{p}_{\mathrm{p}}^{(\mathrm{g})}\right)}{\left(\mathbf{p}_{\mathrm{g}} \times \mathbf{p}_{\mathrm{p}}^{(\mathrm{g})}\right) \times \mathbf{n}_{\mathrm{p}}^{(\mathrm{g})}} \\
\phi_{\mathrm{g} 0}=\frac{\left(\mathbf{p}_{\mathrm{p}}^{(\mathrm{g})} \times \mathbf{p}_{\mathrm{g}}\right)\left(\mathbf{n}_{\mathrm{g}} \times \mathbf{p}_{\mathrm{g}}\right)}{\left(\mathbf{p}_{\mathrm{p}}^{(\mathrm{g})} \times \mathbf{p}_{\mathrm{g}}\right) \times \mathbf{n}_{\mathrm{g}}}
\end{gathered}
$$

Similarly, $\mathbf{R}_{\mathrm{bp}}^{(\phi)}$ and $\mathbf{R}_{\mathrm{bg}}^{(\phi)}$ denote the vectors $\mathbf{R}_{\mathrm{bp}}^{(\mathrm{g})}$ and $\mathbf{R}_{\mathrm{bg}}$ when rotations $\phi_{\mathrm{p}}$ and $\phi_{\mathrm{g}}$ are performed about their respective axes $\mathbf{p}_{\mathrm{p}}^{(\mathrm{g})}$ and $\mathbf{p}_{\mathrm{g}}$, and they are given by

$$
\begin{aligned}
\mathbf{R}_{\mathrm{bp}}^{(\phi)}= & \left(\mathbf{R}_{\mathrm{bp}}^{(\mathrm{g})} \times \mathbf{p}_{\mathrm{p}}^{(\mathrm{g})}\right) \times \mathbf{p}_{\mathrm{p}}^{(\mathrm{g})}+\left(\mathbf{R}_{\mathrm{bp}}^{(\mathrm{g})}-\left(\mathbf{R}_{\mathrm{bp}}^{(\mathrm{g})} \times \mathbf{p}_{\mathrm{p}}^{(\mathrm{g})}\right) \times \mathbf{p}_{\mathrm{p}}^{(\mathrm{g})}\right) \cos \phi_{\mathrm{p}} \\
+ & \mathbf{p}_{\mathrm{p}}^{(\mathrm{g})} \times\left(\mathbf{R}_{\mathrm{bp}}^{(\mathrm{g})}-\left(\mathbf{R}_{\mathrm{bp}}^{(\mathrm{g})} \times \mathbf{p}_{\mathrm{p}}^{(\mathrm{g})}\right) \times \mathbf{p}_{\mathrm{p}}^{(\mathrm{g})}\right) \times \sin \phi_{\mathrm{p}} \\
\mathbf{R}_{\mathrm{bg}}^{(\phi)}= & \left(\mathbf{R}_{\mathrm{bg}} \times \mathbf{p}_{\mathrm{g}}\right) \times \mathbf{p}_{\mathrm{g}}+\left(\mathbf{R}_{\mathrm{g}}-\left(\mathbf{R}_{\mathrm{g}} \times \mathbf{p}_{\mathrm{g}}\right) \times \mathbf{p}_{\mathrm{g}}\right) \cos \phi_{\mathrm{g}}+\mathbf{p}_{\mathrm{g}} \\
& \times\left(\mathbf{R}_{\mathrm{g}}-\left(\mathbf{R}_{\mathrm{g}} \times \mathbf{p}_{\mathrm{g}}\right) \times \mathbf{p}_{\mathrm{g}}\right) \times \sin \phi_{\mathrm{g}}
\end{aligned}
$$

If the gear drive is perfectly aligned, point $O_{\mathrm{p}}$ coincides with point $O_{\mathrm{g}}$, i.e., $\mathbf{R}_{\mathrm{bp}}^{(\phi)}=\mathbf{R}_{\mathrm{bg}}^{(\phi)}$. With the existence of assembling errors, the conjugation of the pinion and gear surface at point $M_{\mathrm{p}}$ must satisfy Condition (b) and the following relation must hold as

$$
\mathbf{R}_{\mathrm{bg}}^{(\phi)}=\mathbf{R}_{\mathrm{bp}}^{(\phi)}+\mathbf{O}_{\mathrm{g}} \mathbf{O}_{\mathbf{p}}=\mathbf{R}_{\mathrm{bp}}^{(\phi)}+\Delta \mathbf{R}_{\mathrm{d}}
$$

As shown in Fig. $1, \Delta \mathbf{R}_{\mathrm{d}}$ can be written as

$$
\Delta \mathbf{R}_{\mathrm{d}}=\Delta J \mathbf{p}_{\mathrm{p}}^{(\mathrm{g})}-\Delta H \mathbf{p}_{\mathrm{g}}-\Delta E \mathbf{e}_{\mathrm{d}}
$$

Substituting Eq. (11) into Eq. (12) and then dotted by $\frac{\mathbf{p}_{\mathrm{g}} \times \mathbf{e}_{\mathrm{d}}}{\mathbf{p}_{\mathrm{p}}^{(\mathrm{g})} \times\left(\mathbf{p}_{\mathrm{g}} \times \mathbf{e}_{\mathrm{d}}\right)}, \frac{\mathbf{e}_{\mathrm{d}} \times \mathbf{p}_{\mathrm{p}}^{(\mathrm{g})}}{\mathbf{p}_{\mathrm{p}}^{(\mathrm{g})} \times\left(\mathbf{p}_{\mathrm{g}} \times \mathbf{e}_{\mathrm{d}}\right)}$, and $\frac{\mathbf{p}_{\mathrm{p}}^{(\mathrm{g})} \times \mathbf{p}_{\mathrm{g}}}{\mathbf{p}_{\mathrm{p}}^{(\mathrm{g})} \times\left(\mathbf{p}_{\mathrm{g}} \times \mathbf{e}_{\mathrm{d}}\right)}$, the position errors can be analytically described as

$$
\left.\begin{array}{c}
\Delta H=-\left(\mathbf{R}_{\mathrm{bg}}^{(\phi)}-\mathbf{R}_{\mathrm{bp}}^{(\phi)}\right) \frac{\mathbf{p}_{\mathrm{g}} \times \mathbf{e}_{\mathrm{d}}}{\mathbf{p}_{\mathrm{p}}^{(\mathrm{g})} \times\left(\mathbf{p}_{\mathrm{g}} \times \mathbf{e}_{\mathrm{d}}\right)} \\
\Delta J=\left(\mathbf{R}_{\mathrm{bg}}^{(\phi)}-\mathbf{R}_{\mathrm{bp}}^{(\phi)}\right) \frac{\mathbf{e}_{\mathrm{d}} \times \mathbf{p}_{\mathrm{p}}^{(\mathrm{g})}}{\mathbf{p}_{\mathrm{p}}^{(\mathrm{g})} \times\left(\mathbf{p}_{\mathrm{g}} \times \mathbf{e}_{\mathrm{d}}\right)} \\
\Delta E=-\left(\mathbf{R}_{\mathrm{bg}}^{(\phi)}-\mathbf{R}_{\mathrm{bp}}^{(\phi)}\right) \frac{\mathbf{p}_{\mathrm{p}}^{(\mathrm{g})} \times \mathbf{p}_{\mathrm{g}}}{\mathbf{p}_{\mathrm{p}}^{(\mathrm{g})} \times\left(\mathbf{p}_{\mathrm{g}} \times \mathbf{e}_{\mathrm{d}}\right)}
\end{array}\right\}
$$

When the position vectors of conjugated point $M_{\mathrm{p}}$ are obtained, the Condition (c) can be expressed as

$$
\begin{aligned}
\mathbf{n}_{\mathrm{p}}^{(\phi)} \times \mathbf{V}_{s} & =\mathbf{n}_{\mathrm{p}}^{(\phi)} \times\left(\frac{d \mathbf{R}_{\mathrm{bg}}^{(\phi)}}{d t}-\frac{d \mathbf{R}_{\mathrm{bp}}^{(\phi)}}{d t}\right) \\
& =\mathbf{n}_{\mathrm{p}}^{(\phi)} \times\left[k \mathbf{p}_{\mathrm{g}} \times \mathbf{R}_{\mathrm{bg}}^{(\phi)}+\mathbf{p}_{\mathrm{p}}^{(\mathrm{g})} \times\left(\mathbf{R}_{\mathrm{bg}}^{(\phi)}-\Delta \mathbf{R}_{\mathrm{d}}\right)\right] \omega_{\mathrm{p}}=0
\end{aligned}
$$

where $k=N_{\mathrm{zp}} / N_{\mathrm{zg}}$ is the gear ratio, $N_{\mathrm{zp}}$ and $N_{\mathrm{zg}}$ denote the tooth number of the pinion and gear, and $\omega_{\mathrm{p}}$ represents the rotational speed of the pinion.

It is noted that position errors $\Delta H, \Delta J, \Delta E$, and $\Delta \sigma$ are included in Eqs. (13) and (14), which are solved to obtain the corresponding conjugation points on the pinion and gear tooth surface with the rotation of the pinion about its axis. The principle curvature and directions are key parameters for lubrication analysis. The geometry of tooth surfaces is attained from the cutting of blade, i.e., the principal curvatures correlate to the relative kinematics between the cutting blade and gear blank. Detailed descriptions of surface parameters can be found in Refs. [8, 37, 39]. 


\section{Asperity stress cycle model}

In general, grinding is an important method for gear machining, in terms of reducing the surface roughness and improving the accuracy of the tooth profiles. The roughness of the grinded surface can be contributed by two parts [42], one is the contact trace between the grinding wheel and the gear, and the other is the uncut zone due to the discretization of the generating movement. As shown in Fig. 2, the curve $l_{M}$ on the gear flank represents the cut trace caused by the grinding wheel. In fact, the cut zone and uncut zone both

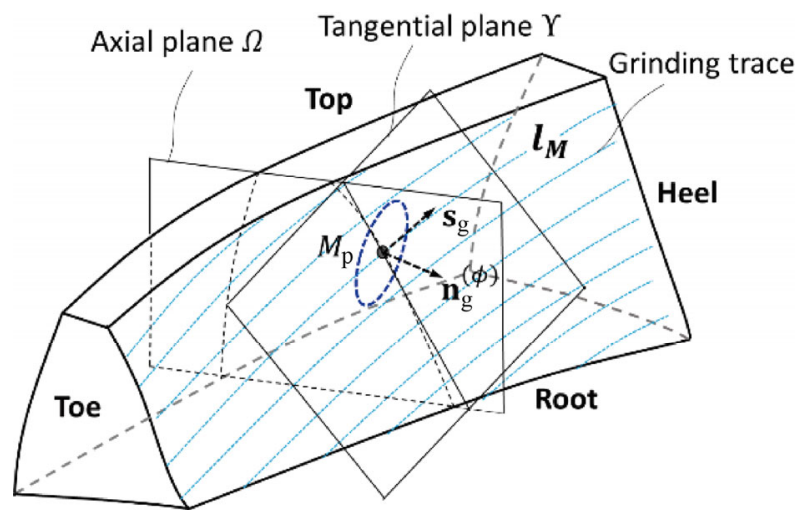

Fig. 2 The roughness caused by grinding traces.
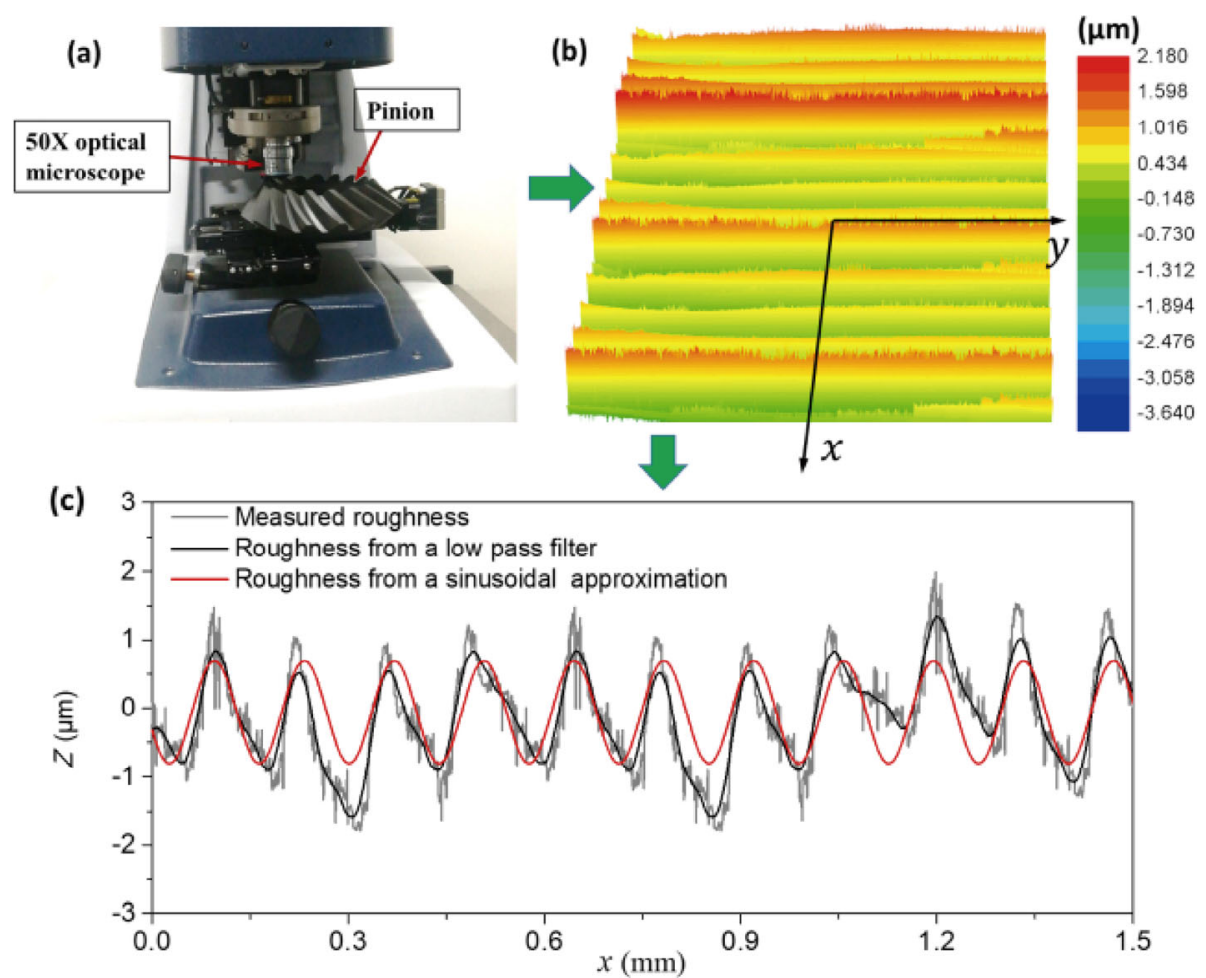

Fig. 3 Measurement of flank roughness in spiral bevel gears: (a) mounting of the pinion on the optical microscope, (b) measured surface roughness, and (c) sinusoidal approximation of roughness. 
bevel gear is elliptical due to the elastic deformation $[8,39,40]$, as shown in Fig. 4 . It is notable that the contact ellipse and roughness are both projected in the tangential plane $\Upsilon$ as described in Fig. 2 to express the effect of sliding on stress cycles.

In Fig. $4, \mathbf{u}_{1}$ and $\mathbf{u}_{2}$ are the velocity vectors of the pinion and gear surface, and $\mathbf{V}_{\mathrm{s}}$ represents the sliding velocity vector. The experienced stress cycle for a certain point is closely related to the roughness peak density of its mating surface. According to Fig. 4, the velocity vector of the pinion surface $\mathbf{u}_{1}$ shows angles of $\theta_{x 1}$ and $\theta_{1}$ with respect to the roughness direction $x^{\prime}$ and minor axis of contact ellipse. Then the time required for a certain asperity of the pinion flank to pass through the contact zone $A B$ can be expressed as

$$
T=\frac{A B}{\left|\mathbf{u}_{1}\right|}=\frac{2 \sqrt{\left(a \sin \theta_{1}\right)^{2}+\left(b \cos \theta_{1}\right)^{2}}}{\left|\mathbf{u}_{1}\right|}
$$

where the velocity vector $\mathbf{u}_{1}$ and the lengths of semimajor and minor axis ( $a$ and $b$ ) can be obtained from the TCA [8].

The sliding distance along the direction of the sliding vector $\mathbf{V}_{\mathrm{s}}$ is given by

$$
s_{\mathrm{d}}=\left|\mathbf{V}_{\mathrm{s}}\right| T=\left|\mathbf{u}_{2}-\mathbf{u}_{1}\right| T=\left|\mathbf{u}_{2}-\mathbf{u}_{1}\right| \frac{2 \sqrt{\left(a \sin \theta_{1}\right)^{2}+\left(b \cos \theta_{1}\right)^{2}}}{\left|\mathbf{u}_{1}\right|}
$$

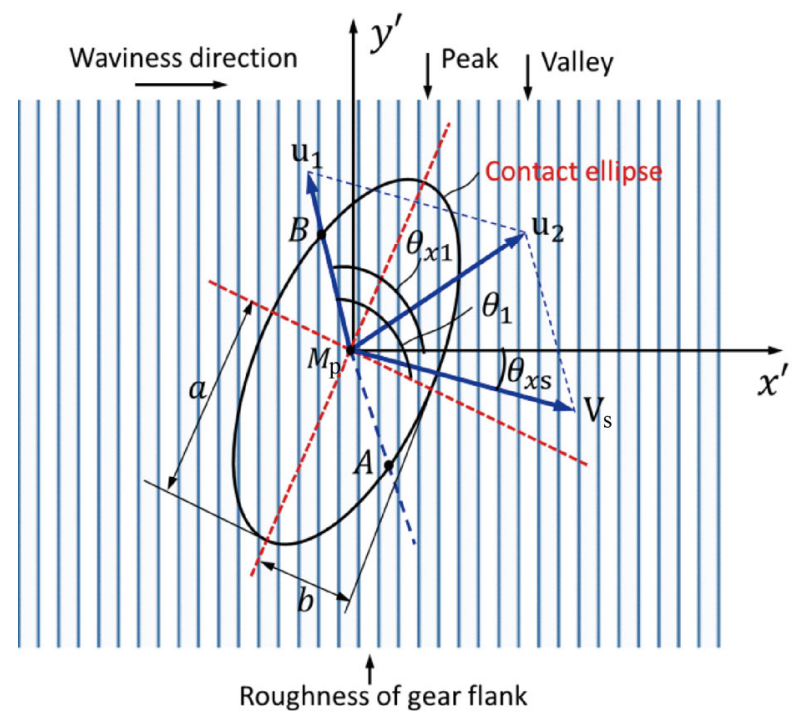

Fig. 4 Contact geometry in tangential plane $\Upsilon$.
Considering the asperity peak densities are $d_{\mathrm{s} 1}$ and $d_{\mathrm{s} 2}$, the number of asperity contacts for Surface 1 during a loading cycle is described as

$$
\begin{aligned}
n_{1} & =1+s_{\mathrm{d}} d_{\mathrm{s} 2} \cos \left(\theta_{x \mathrm{~s} 1}\right) \\
& =1+\left|\mathbf{u}_{2}-\mathbf{u}_{1}\right| \frac{2 \sqrt{\left(a \sin \theta_{1}\right)^{2}+\left(b \cos \theta_{1}\right)^{2}}}{\left|\mathbf{u}_{1}\right|} d_{\mathrm{s} 2} \cos \left(\theta_{x \mathrm{~s} 1}\right)
\end{aligned}
$$

where $\theta_{x s 1}$ denotes the angle between $\mathbf{V}_{\mathrm{s}}$ and $x^{\prime}$ axis (the waviness direction of gear flank roughness). Note that the asperity density is commonly measured along the waviness direction, hence, $d_{\mathrm{s} 2} \cos \left(\theta_{x \mathrm{~s}}\right)$ represents the component of sliding distance in the direction of $x^{\prime}$. For Surface 2, the number of asperity contacts can be easily obtained through the similar procedure using Eqs. (15) and (16). For brevity, the analogical expression of asperity contacts for Surface 2 is described as

$$
\begin{aligned}
n_{2} & =1+s_{\mathrm{d}} d_{\mathrm{s} 1} \cos \left(\theta_{x \mathrm{~s} 2}\right) \\
& =1+\left|\mathbf{u}_{2}-\mathbf{u}_{1}\right| \frac{2 \sqrt{\left(a \sin \theta_{2}\right)^{2}+\left(b \cos \theta_{2}\right)^{2}}}{\left|\mathbf{u}_{2}\right|} d_{\mathrm{s} 1} \cos \left(\theta_{x \mathrm{~s} 2}\right)
\end{aligned}
$$

According to Eq. (17a), it is evident that the number of stress cycles for Surface 1 is related to the velocity vectors $\mathbf{u}_{1}$ and $\mathbf{u}_{2}$, and angles $\theta_{1}$ and $\theta_{x \mathrm{~s}}$. Taking Surface 1 as an example, mathematical derivations are described to make Eq. (17a) executable. Note that the subsequent derivation process of Eq. (17b), which is omitted here, follows a similar procedure to that of Eq. (17a).

The angle $\left(\theta_{1}\right)$ between the velocity of the pinion surface and minor axis of the contact ellipse is computed through vector operations, as described in Ref. [8]. The velocity vectors are given by

$$
\left.\begin{array}{l}
\mathbf{u}_{1}=\omega_{\mathrm{p}} \mathbf{p}_{\mathrm{p}}^{(\mathrm{g})} \times \mathbf{R}_{\mathrm{bp}}^{(\phi)}=\mathbf{p}_{\mathrm{p}}^{(\mathrm{g})} \times\left(\mathbf{R}_{\mathrm{bg}}^{(\phi)}-\Delta \mathbf{R}_{\mathrm{d}}\right) \\
\mathbf{u}_{2}=\omega_{\mathrm{p}} \kappa \mathbf{p}_{\mathrm{g}} \times \mathbf{R}_{\mathrm{bg}}^{(\phi)}
\end{array}\right\}
$$

According to Eqs. (9) and (10), $\mathbf{R}_{\mathrm{bp}}^{(\phi)}$ and $\mathbf{R}_{\mathrm{bg}}^{(\phi)}$ are transformed from position vectors $\mathbf{R}_{\mathrm{bp}}$ and $\mathbf{R}_{\mathrm{bg}} \cdot \kappa$ denotes the tooth number ratio between the gear and pinion. During the meshing process, the position vectors $\mathbf{R}_{\mathrm{bp}}$ and $\mathbf{R}_{\mathrm{bg}}$ are calculated based on the 
rotational projection, and the projection plane is defined by an axial plane $\Omega$ in Fig. 5 .

For the meshing position $A\left(x_{a i}^{(\mathrm{g})}, y_{a i}^{(\mathrm{g})}\right)$ on the gear flank, the position vector $\mathbf{R}_{\mathrm{bg}}$ is computed by

$$
\left.\begin{array}{l}
\left|\mathbf{R}_{\mathrm{bg}} \times \mathbf{p}_{\mathrm{g}}\right|=x_{a i}^{(\mathrm{g})} \\
\left|\mathbf{R}_{\mathrm{bg}} \times \mathbf{p}_{\mathrm{g}}\right|=y_{a i}^{(\mathrm{g})}
\end{array}\right\}
$$

Similarly, the position vector $\mathbf{R}_{\mathrm{bp}}$ can also be obtained from above relationship.

The tangential plane varies at different meshing positions and consequently, the waviness roughness direction, which can be attained from the optical profiler, is first projected in the axial projection plane to determine the direction of the roughness in the gear flank for convenience. In the coordinate system $\sum\left(o_{g}, \mathbf{i}_{g}, \mathbf{j}_{g}\right)$ of the axial plane as shown in Fig. $5, \mathbf{i}_{\mathrm{g}}$ and $\mathbf{j}_{\mathrm{g}}$ are introduced as

$$
\left.\begin{array}{l}
\mathbf{i}_{\mathrm{g}}=-\mathbf{p}_{\mathrm{g}} \\
\mathbf{j}_{\mathrm{g}}=\frac{\mathbf{p}_{\mathrm{g}} \times\left(\mathbf{R}_{\mathrm{bg}}^{(\phi)} \times \mathbf{p}_{\mathrm{g}}\right)}{\left|\mathbf{R}_{\mathrm{bg}}^{(\phi)} \times \mathbf{p}_{\mathrm{g}}\right|}
\end{array}\right\}
$$

Note that, as plotted in Fig. 2, the surface unit normal vector of gear flank $\mathbf{n}_{\mathrm{g}}^{(\phi)}$ is orthogonal to the tangential plane $\Upsilon$, and the direction unit vector $\mathbf{s}_{\mathrm{g}}$ of roughness exists in the tangential plane $\Upsilon$. According to vector operations, $\mathbf{s}_{\mathrm{g}}$ can be solved by

$$
\left.\begin{array}{l}
\tan \theta_{\mathrm{sg}}=\frac{\mathbf{s}_{\mathrm{g}} \times \mathbf{j}_{\mathrm{g}}}{\mathbf{s}_{\mathrm{g}} \times \mathbf{i}_{\mathrm{g}}} \\
\mathbf{n}_{\mathrm{g}}^{(\phi)} \times \mathbf{s}_{\mathrm{d}}=0
\end{array}\right\}
$$

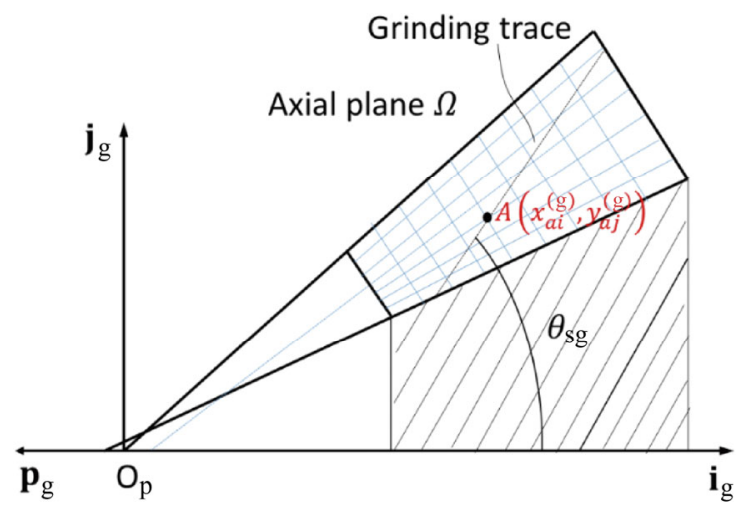

Fig. 5 Gear flank and roughness direction in axial plane $\Omega$.
Finally, $\theta_{x s 1}$ in Eq. (17) can be easily obtained by

$$
\theta_{x \mathrm{~s} 1}=\frac{\pi}{2}-\arccos \left(\mathbf{s}_{\mathrm{g}} \times \mathbf{V}_{\mathrm{s}}\right)
$$

\section{Mixed EHL and fatigue prediction model}

\subsection{Mixed EHL model in spiral bevel gears}

A mixed EHL model for spiral bevel gears has been employed to simulate the asperity contact and lubricant pressure distributions [8]. The mixed EHL model for line and point contact has been unified by Zhu et al. $[19,22,25,26]$, and then modified in Refs. $[8,32]$ to investigate the lubrication performance of spiral bevel gears, in which the entraining vector has an angle with the minor axis of the Hertzian ellipse. The modified Reynolds equation is expressed as

$$
\begin{aligned}
& \frac{\partial}{\partial x}\left(\frac{\rho h^{3}}{12 \eta} \frac{\partial p}{\partial x}\right)+\frac{\partial}{\partial y}\left(\frac{\rho h^{3}}{12 \eta} \frac{\partial p}{\partial y}\right) \\
& =\left|\mathbf{U}_{\mathrm{e}}\right| \cos \theta_{\mathrm{e}} \times \frac{\partial(\rho h)}{\partial x}+\left|\mathbf{U}_{\mathrm{e}}\right| \sin \theta_{\mathrm{e}} \times \frac{\partial(\rho h)}{\partial y}+\frac{\partial(\rho h)}{\partial t}
\end{aligned}
$$

Note that the directions of $x$ and $y$ axes for the Reynolds equation coincide with the minor and major axes of the contact ellipse, respectively, which are different from the coordinates described in Fig. 4. The entraining velocity vector $\mathbf{U}_{\mathrm{e}}=\left(\mathbf{u}_{1}+\mathbf{u}_{2}\right) / 2$ has an angle $\theta_{\mathrm{e}}$ with the minor axis of the Herztian contact ellipse. The computation method for $\theta_{\mathrm{e}}$ has been explained in Ref. [8] in detail. $p$ denotes the pressure distributions in the contact zone, including the asperity contact and film pressure.

The local film thickness and pressure in the Reynolds equation are interdependent. As mentioned earlier, the $3 \mathrm{D}$ roughness may cause pressure peaks, which can further cause a high stress concentration. The film thickness introduced in the 3D roughness is expressed as

$$
h=h_{0}(t)+g(x, y, t)+\delta_{1}(x, y, t)+\delta_{2}(x, y, t)+V(x, y, t)
$$

where $h_{0}(t)$ denotes the normal approach of two surfaces, $\delta_{1}(x, y, t)$ and $\delta_{2}(x, y, t)$ represent the $3 \mathrm{D}$ roughness of two surfaces measured from the optical 
interferometer. $g(x, y, t)=x^{2} / 2 R_{x}+y^{2} / 2 R_{y}$ describes the contact geometry by contact curvatures, where the equivalent radius $R_{x}$ and $R_{y}$ along the minor axis and major axis of contact ellipse are obtained from the TCA as described in Ref. [8] in detail. The elastic deformation $(V(x, y, t))$, can be attained by

$$
V_{\mathrm{e}}(x, y, t)=\frac{2}{\pi E^{\prime}} \iint_{\Omega} \frac{p(\xi, \zeta)}{\sqrt{(x-\xi)^{2}+(y-\zeta)^{2}}} \mathrm{~d} \xi \mathrm{d} \zeta
$$

The commonly used lubricant viscosity model, as a function of pressure and temperature, can be given by

$$
\eta=\eta_{0} \exp \left[\alpha p+(\beta+\chi p)\left(\frac{1}{T}-\frac{1}{T_{0}}\right)\right]
$$

The lubricant density is assumed dependent on pressure, which is written as

$$
\rho=\rho_{0}\left(1+\frac{0.6 \times 10^{-9} p}{1+1.7 \times 10^{-9} p}\right)
$$

The load between the tooth mating surfaces is supported by the lubricant and asperity contact, and the balance equation is given as

$$
F_{m}(t)=\iint_{\Omega} p(x, y, t) \mathrm{d} x \mathrm{~d} y
$$

The friction computation is based on the film and pressure distributions that are derived from Eqs. (2328). Newtonian fluid model or non-Newtonian fluid model can be used as the rheological model for different lubrication and operating conditions. Generally, the lubricant presents non-Newtonian behavior, especially under the high load and large sliding condition in spiral bevel gears. In the present study, the shear stress in the hydrodynamic areas is estimated using a viscoelastic non-Newtonian fluid model proposed by Bair and Winer [44] expressed as

$$
\gamma^{\prime}=\frac{\tau^{\prime}}{G_{\infty}}-\frac{\tau_{\mathrm{L}}}{\eta} \ln \left(1-\frac{\tau}{\tau_{\mathrm{L}}}\right) \approx \frac{\left|\mathbf{V}_{\mathrm{s}}\right|}{h}
$$

In Eq. (29), the limiting shear stress $\left(\tau_{\mathrm{L}}\right)$ and the limiting shear elastic modulus $\left(G_{\infty}\right)$ are empirically defined as functions of pressure and temperature, as described in Refs. [19, 43].

In the mixed lubrication regime, the asperity contact and hydrodynamic area can coexist. The friction coefficient in the contact area (boundary lubrication) is commonly considered as a constant to be determined experimentally. Therefore, the total friction is obtained through the integration of the shear stress covering the hydrodynamic area and contact area $[19,43]$. As mentioned in Eq. (29), friction can be affected by temperature, whilst the temperature rise is caused by the generated friction heat. Consequently, it is necessary to take into account the mutual effects between the friction and flash temperature in the calculation of shear stress. The solution for flash temperature is based on the case of a moving heat source over a semi-infinite solid, and the detailed derivation can be found in Ref. [43].

$$
\begin{aligned}
& T_{1}(\xi)=T_{\mathrm{b} 1} \\
& +\left(\frac{1}{\pi \rho_{1} C_{1} u_{1} k_{1}}\right)^{0.5} \int_{-x}^{\xi}\left\{\frac{k_{f}}{h}\left[T_{2}(\lambda)-T_{1}(\lambda)\right]+\frac{q(\lambda)}{2}\right\} \times \frac{d(\lambda)}{(\xi-\lambda)^{0.5}}
\end{aligned}
$$

$$
\begin{aligned}
& T_{2}(\xi)=T_{\mathrm{b} 2} \\
& +\left(\frac{1}{\pi \rho_{2} C_{2} u_{2} k_{2}}\right)^{0.5} \int_{-x}^{\xi}\left\{\frac{k_{f}}{h}\left[T_{1}(\lambda)-T_{2}(\lambda)\right]+\frac{q(\lambda)}{2}\right\} \times \frac{d(\lambda)}{(\xi-\lambda)^{0.5}}
\end{aligned}
$$

where $T_{1}$ and $T_{2}$ denote the flash temperature for two mating surfaces, $C_{1}$ and $C_{2}$ are the specific heat of two bodies, $k_{1}=k_{2}$ represents the thermal conductivity of the lubricant, and $\rho_{1}$ and $\rho_{2}$ are the density of pinion and gear materials. $q=\tau \times\left|\mathbf{V}_{s}\right|$ represents the friction heat generated by the viscous force and asperity contact shear.

\subsection{Fatigue life model}

A famous RCF model for rolling element bearing was proposed by Lundberg and Palmgren [9] and then modified by Ioannides and Harris [11] and Zaretsky [12] for a wider application, such as spur gears and helical gears. In comparison with the Ioannides-Harris model, the Zaretsky model dropped the stress depth factor (first introduced in Ref. [9]) and the fatigue limit stress (first involved in Ref. [11]). In the present study, stress is obtained from the mixed EHL model 
deterministically, therefore, the stress depth factor is no longer needed. Besides, the fatigue limit stress is difficult to be determined for engineering applications due to the lack of reliable experimental data [17]. Therefore, the Zaretsky model [12] is adopted in this study for the fatigue prediction of spiral bevel gears. The fatigue life is defined by the number of stress cycles $M$ until pitting under a given probability of failure $P_{\mathrm{s}}$, as expressed by

$$
\ln \frac{1}{P_{\mathrm{s}}} \approx M^{e} \iiint_{V} \sigma_{\text {eff }}^{\mathrm{ec}} \mathrm{d} V
$$

where the Weibull slope $e$ and stress exponent $c$ can be determined experimentally. $V$ represents the material volume affected by effective stress $\sigma_{\text {eff }}$. The octahedral stress is used as the effective stress $\sigma_{\text {eff }}$, as given by

$$
\begin{aligned}
\sigma_{\text {eff }}= & \frac{1}{3}\left[\left(\sigma_{x}-\sigma_{y}\right)^{2}+\left(\sigma_{y}-\sigma_{z}\right)^{2}+\left(\sigma_{z}-\sigma_{x}\right)^{2}\right. \\
& \left.+6\left(\tau_{x y}^{2}+\tau_{y z}^{2}+\tau_{z x}^{2}\right)\right]^{\frac{1}{2}} \quad(i=x, y, z ; j=x, y, z)
\end{aligned}
$$

where $\sigma_{i}$ and $\tau_{i j}$ are the normal and tangential components of the octahedral stress. The interior stress components are calculated based on the pressure distribution and friction shear stress obtained from the mixed EHL model (detailed derivations can be found in Ref. [45]).

The number of stress cycles $M$ of the RCF fatigue model is conventionally assumed to equal that of loading cycles or revolution cycles, rather than the number of the actual loading-unloading cycles at a certain point experienced by a series of micro asperities. The RCF fatigue model has been verified theoretically and experimentally in spur gears [17] and rolling element bearings [11] with insignificant sliding. However, as discussed, the actual stress cycles may be significantly enlarged due to the presence of sliding for transverse rough surfaces, i.e., $M=N \times n$, where $N$ is the number of revolutions or component loading cycles, and $n$ is the number of asperity experience per revolution or loading cycle as derived in Eq. (17). Consequently, $1 / n$, as the reduction factor for the fatigue life $M$ introduced by asperity cycle counting, is a function of velocity vectors, contact geometry, and asperity density of the mating surface in spiral bevel gears.

\section{Results and discussion}

\subsection{TCA results under different misalignments}

In this study, a spiral bevel gear pair with 25-34 teeth is employed and its parameters and machining settings are summarized in Tables 1 and 2, respectively. As shown in Fig. 1, there are four types of misalignments, which can be denoted as $\Delta H, \Delta J, \Delta E$, and $\Delta \sigma$. Due to the assembling errors and the deflections of the support system, the position of the contact area on the tooth surface is different from the designed contact position in the actual operation. To ensure a better transmission under different working conditions, it is necessary to observe simultaneously the contact quality under the change of the relative positions of the two axes, so that the contact area is moved to the heel and toe of the tooth surface. In addition, the relative positions of the pinion and gear can also be affected by the angle between two axes, and the contact pattern needs to be tested under different angle errors during the machining process. Hence, four representative cases of displacement errors are shown in Table 3 and their corresponding contact trajectories, as obtained from the proposed method in Section 2, are plotted in Fig. 6 . The contact geometry (expressed by curvatures $R_{z x}$ and $R_{z y}$ along the minor and major axis of the contact ellipse), velocity parameters, and contact loads are the main input data for the mixed EHL analysis [8]. As shown in Figs. 8 and 9, the varying assembling misalignments can significantly affect the meshing parameters, which may further influence the lubrication

Table 1 Parameters of gear and pinion.

\begin{tabular}{ccc}
\hline & Pinion & Gear \\
\hline Number of teeth & 25 & 34 \\
Module & \multicolumn{3}{c}{$5.0 \mathrm{~mm}$} \\
Tooth width & \multicolumn{3}{c}{$30 \mathrm{~mm}$} \\
Average pressure angle & \multicolumn{3}{c}{$20^{\circ}$} \\
Mean spiral angle & $35^{\circ}$ \\
Shaft angle & \multicolumn{3}{c}{$90^{\circ}$} \\
Face angle & $39^{\circ} 38^{\prime}$ & $56^{\circ} 00^{\prime}$ \\
Pitch angle & $36^{\circ} 20^{\prime}$ & $53^{\circ} 40^{\prime}$ \\
Root angle & $34^{\circ} 00^{\prime}$ & $50^{\circ} 22^{\prime}$ \\
Outside diameter & $133.29 \mathrm{~mm}$ & $173.97 \mathrm{~mm}$ \\
Hand of spiral & Left & Right \\
\hline
\end{tabular}


Table 2 Machining settings.

\begin{tabular}{cccc}
\hline & \multicolumn{2}{c}{ Pinion } & Gear \\
\cline { 2 - 3 } & Concave & Convex & \\
\hline Mea cutter radius & $146.07 \mathrm{~mm}$ & $158.65 \mathrm{~mm}$ & $165.00 \mathrm{~mm}$ \\
Point width & $2.79 \mathrm{~mm}$ & $2.79 \mathrm{~mm}$ & $2.79 \mathrm{~mm}$ \\
Blade angle & $18^{\circ} 00^{\prime}$ & $22^{\circ} 00^{\prime}$ & $\begin{array}{c}\text { Concave: } 18^{\circ} 05^{\prime} \\
\text { Convex: } 21^{\circ} 55\end{array}$ \\
Root angle & \multicolumn{2}{c}{$34^{\circ} 00^{\prime}$} & $50^{\circ} 22^{\prime}$ \\
Work head & $-2.09 \mathrm{~mm}$ & $2.10 \mathrm{~mm}$ & 0.00 \\
Sliding base & $1.16 \mathrm{~mm}$ & $-1.18 \mathrm{~mm}$ & 0.00 \\
Offset & $1.99 \mathrm{~mm}$ & $-2.11 \mathrm{~mm}$ & 0.00 \\
Cradle angle & $124^{\circ} 10^{\prime}$ & $124^{\circ} 57^{\prime}$ & $16^{\circ} 19^{\prime}$ \\
Eccentric angle & $40^{\circ} 390^{\prime}$ & $41^{\circ} 33^{\prime}$ & $41^{\circ} 06^{\prime}$ \\
Radial distance & $77.21 \mathrm{~mm}$ & $78.83 \mathrm{~mm}$ & $78.01 \mathrm{~mm}$ \\
Ratio of roll & $1.69 \mathrm{~mm}$ & $1.68 \mathrm{~mm}$ & $1.24 \mathrm{~mm}$ \\
\hline
\end{tabular}

Table 3 Four representative misalignment combinations.

\begin{tabular}{ccccc}
\hline & $\Delta H$ & $\Delta J$ & $\Delta E$ & $\Delta \sigma$ \\
\hline Case (a) & $1.35 \mathrm{~mm}$ & $0.83 \mathrm{~mm}$ & $-1.63 \mathrm{~mm}$ & 0 \\
Case (b) & $-0.30 \mathrm{~mm}$ & $-0.77 \mathrm{~mm}$ & $0.86 \mathrm{~mm}$ & 0 \\
Case (c) & 0 & 0 & 0 & $-0.40^{\circ}$ \\
Case (d) & 0 & 0 & 0 & $0.40^{\circ}$ \\
\hline
\end{tabular}

performance and fatigue life. Note that the applied rotational speed and the torque acting on gear are $100 \mathrm{r} / \mathrm{min}$ and $93.0 \mathrm{~N} \cdot \mathrm{m}$, respectively.

\subsection{Fatigue life analysis}

As mentioned previously, the contact pressure and shear stress distribution from the mixed EHL analysis is the key to the fatigue life prediction. Taking the TCA results as the input, the lubrication performance is investigated for further fatigue life estimation, as shown in Fig. 10. The material properties of the pinion and gear are characterized by the effective elastic modulus ( $E^{\prime}=219.78 \mathrm{GPa}$ ) and hardness $(7.0 \mathrm{GPa})$. A typical mineral lubricant is used with the dynamic viscosity $\eta_{0}=0.09 \mathrm{~Pa} \cdot \mathrm{s}$ and viscosity-pressure coefficient $\alpha=12.5 \mathrm{GPa}^{-1}$. As depicted in Fig. 3, the grinded surface profiles in spiral bevel gears are measured by the optical profiler, and the roughness is $0.36 \mu \mathrm{m}$ for the pinion and $0.41 \mu \mathrm{m}$ for the gear flank, with a RMS roughness of $0.55 \mu \mathrm{m}$. After the sinusoidal approximation for the grinded roughness, the densities of roughness $d_{\mathrm{s} 1}$ and $d_{\mathrm{s} 2}$ are found to be 9.265 and 9.486 per millimeter, respectively. The
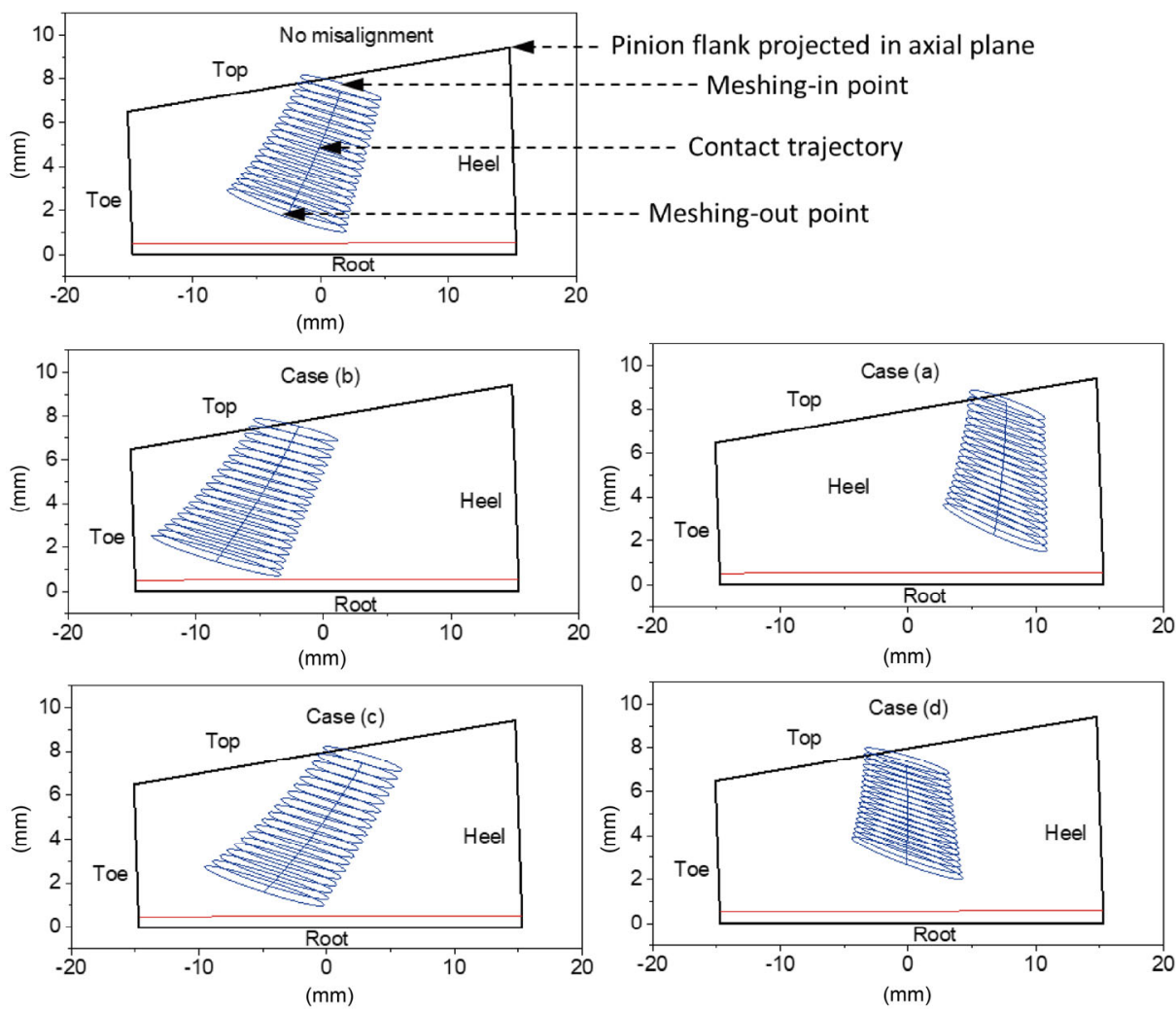

Fig. 6 Contact trajectories under different error combinations. 

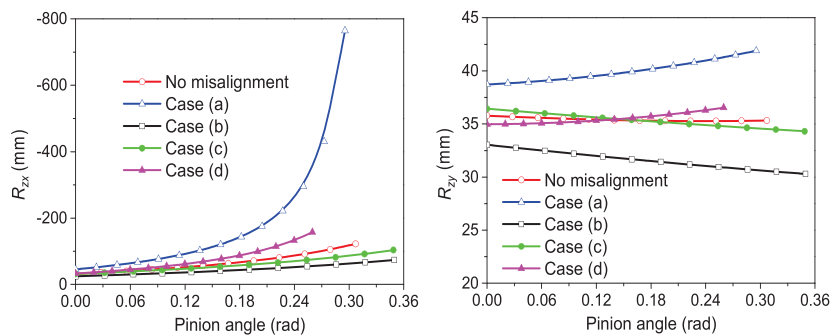

Fig. 7 Radii of curvatures $R_{z x}$ and $R_{z y}$ along the minor and major axes of contact ellipse.
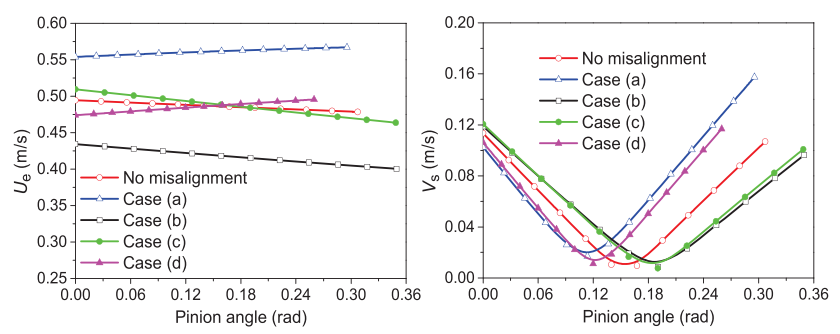

Fig. 8 Entrainment velocity and sliding velocity in a mesh cycle.
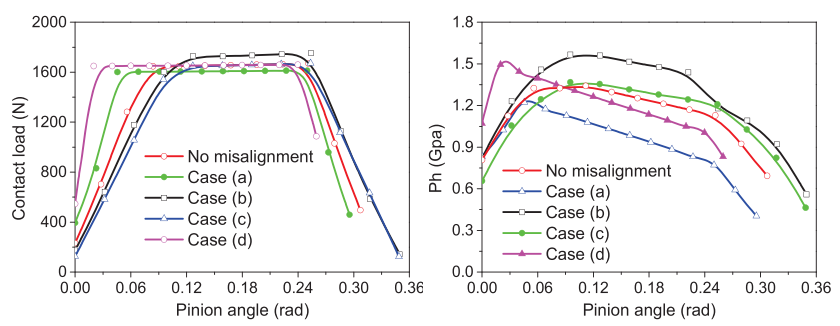

Fig. 9 Contact load and the maximum Hertzian pressure under different error combinations.

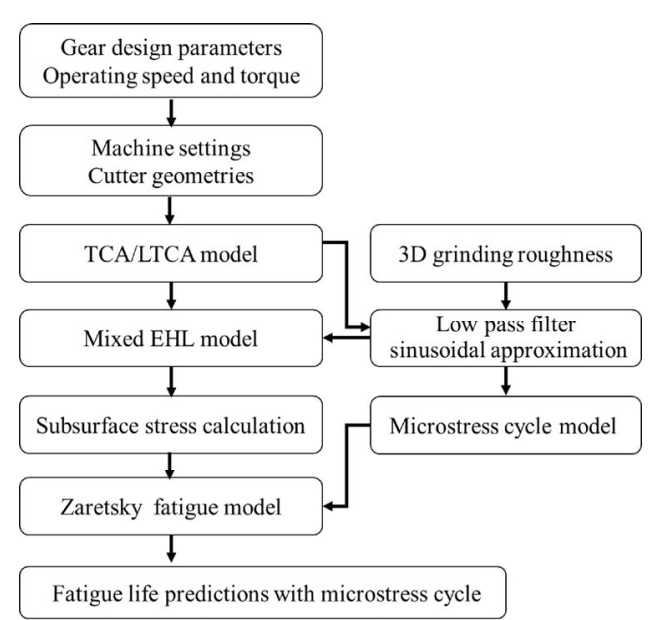

Fig. 10 Methodology of fatigue prediction with microstress cycle.

solution domain for the Reynolds equation are defined by $-2 \leqslant X=x / a \leqslant 2$ and $-2 \leqslant Y=y / a \leqslant 2$, and the dimensionless time step is given by $\Delta=\left(\left|\mathbf{U}_{\mathrm{e}}\right| \Delta t\right) / a=0.005$. A grid with $257 \times 257$ equally spaced nodes is used to discretize the solution domain, resulting in a dimensionless equal spacing of $\Delta X=\Delta Y=0.015625$. The judgment for pressure convergence is set by $\varepsilon_{\mathrm{p}}=\sum\left|p_{i, j}^{\text {New }}-p_{i, j}^{\text {Old }}\right| / \sum p_{i, j}^{\text {New }}<0.0001$.

The normal micro-pressure distribution related to the subsurface stress is an important parameter in Zaretsky's fatigue model [12], especially for the case of asperity contact. The pressure distributions for the no misalignment case at different meshing points are shown in Fig. 11. The top left corner of Fig. 11 describes the pressure contour at the meshing-in position, in which the contact zone is of the shape of a circle due to the non-dimensionalization of the contact ellipse, and the pressure along $X$ direction is shown in Fig. 11. It is obvious that the pressure and oil film distributions appear differently at different positions, and the pressure is relatively high with zero film thickness due to the asperity contact. According to Fig. 9, the maximum Hertzian pressure for the meshing-in point and the pinion angle of $0.084 \mathrm{rad}$ are 0.807 and $1.32 \mathrm{GPa}$, respectively, although the pressure peak of the former (3.5 GPa) is larger than that of the latter $(1.86 \mathrm{GPa})$. This is because the difference in the contact position can result in 7 and 13 asperity contacts for meshing-in point and pinion angle of $0.084 \mathrm{rad}$, respectively. There are also 13 pressure peaks for the pinion angle of $0.31 \mathrm{rad}$ (the meshing-out point). Obviously, smaller Hertzian contact pressure causes lower asperity pressure peak compared with that of the meshing-in point, as shown in Figs. 9 and 11. Hence, the mesh load, contact geometry, and asperity can all affect the pressure distributions, which may lead to the variations of subsurface stress and consequently, a significant influence on fatigue life.

As manifested in Fig. 11, the pressure peaks resulted from the asperity contact are considerably higher than the maximum Hertzian pressure, whilst the micro pressure at the roughness valley is apparently low as compared to the pressure peaks. It is shown that the surface of the gear flank experiences the "loadingunloading" cycle under the rolling-sliding motion. This kind of cycle is used to define the fatigue life $M$ as described in Eq. (32). As mentioned in Zaretsky's model [12], the fatigue life is evaluated through the effective stress and the material volume affected by stress. For the rolling-sliding contact, both normal 

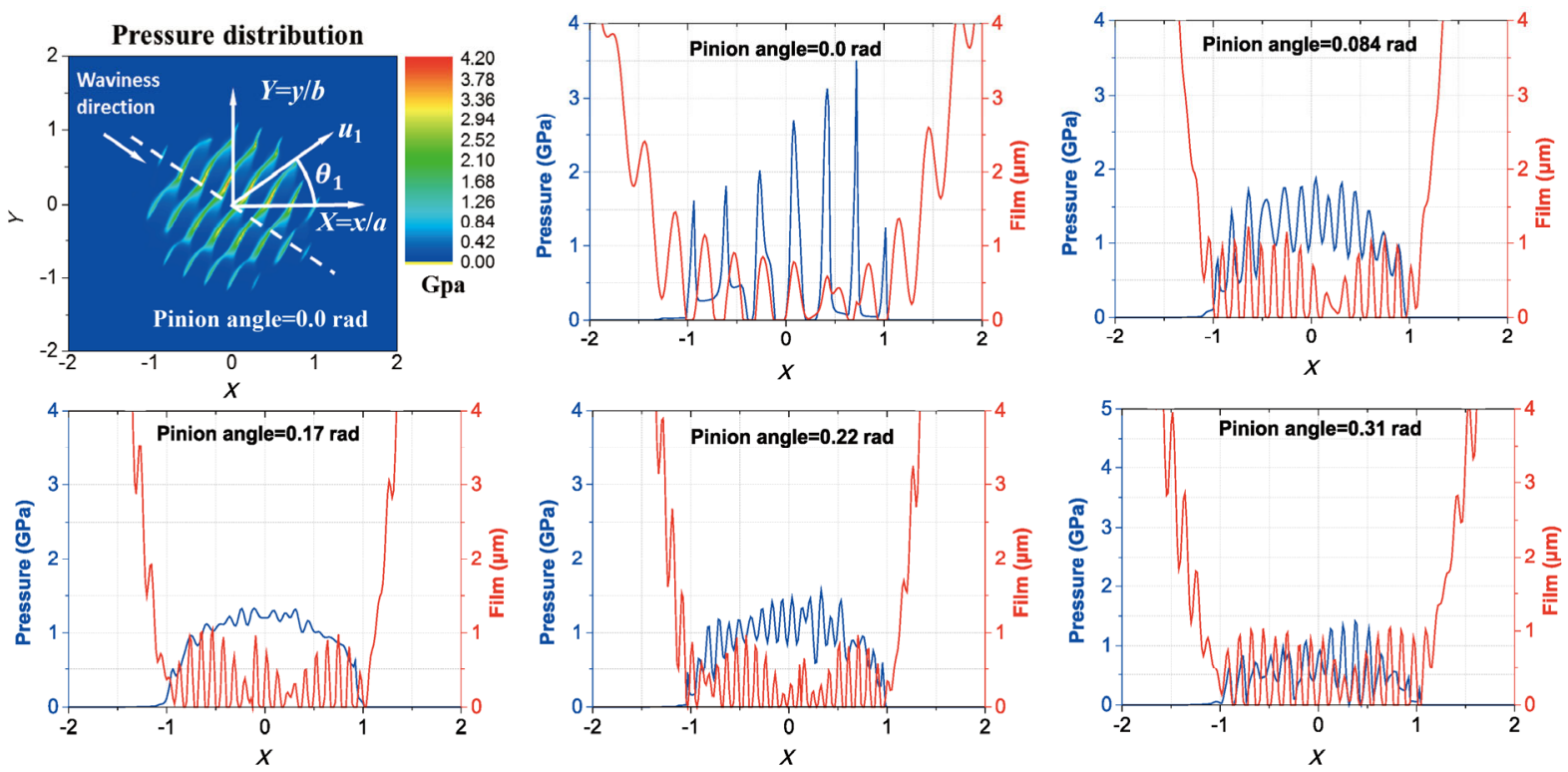

Fig. 11 Pressure distributions at different meshing positions.

contact pressure and friction shear, as obtained from the mixed EHL analysis for spiral bevel gears, contribute to the normal and tangential stress components, $\sigma_{i}$ and $\tau_{i j}$. The subsurface stress distributions at different meshing points for the case of no misalignment are plotted in Fig. 12 and the octahedral stresses along the centerline cross section is summarized ( $Z$ direction points to the body of the gear flank). It can be observed that the local high stress concentrations at meshing-in points are induced by pressure peaks caused by the asperities that move toward the surface of the gear flank, as compared to the stress distributions of smooth surfaces. If the machined surface is ideally smooth, the critical stress plane occurs beneath the surface and its stress experiences are equal to the macro-loading cycles. However, these discontinuous asperities result in high-low stress cycles in the contact zone under the sliding condition, which may lead to a reduction of fatigue life due to the increased number of asperity contacts as explained mathematically in Eq. (17). Additionally, with further meshing, the maximum stress decreases and occurs at the subsurface.

For each transient meshing position, the stress distributions obtained from Eq. (33) are used in Eq. (32)
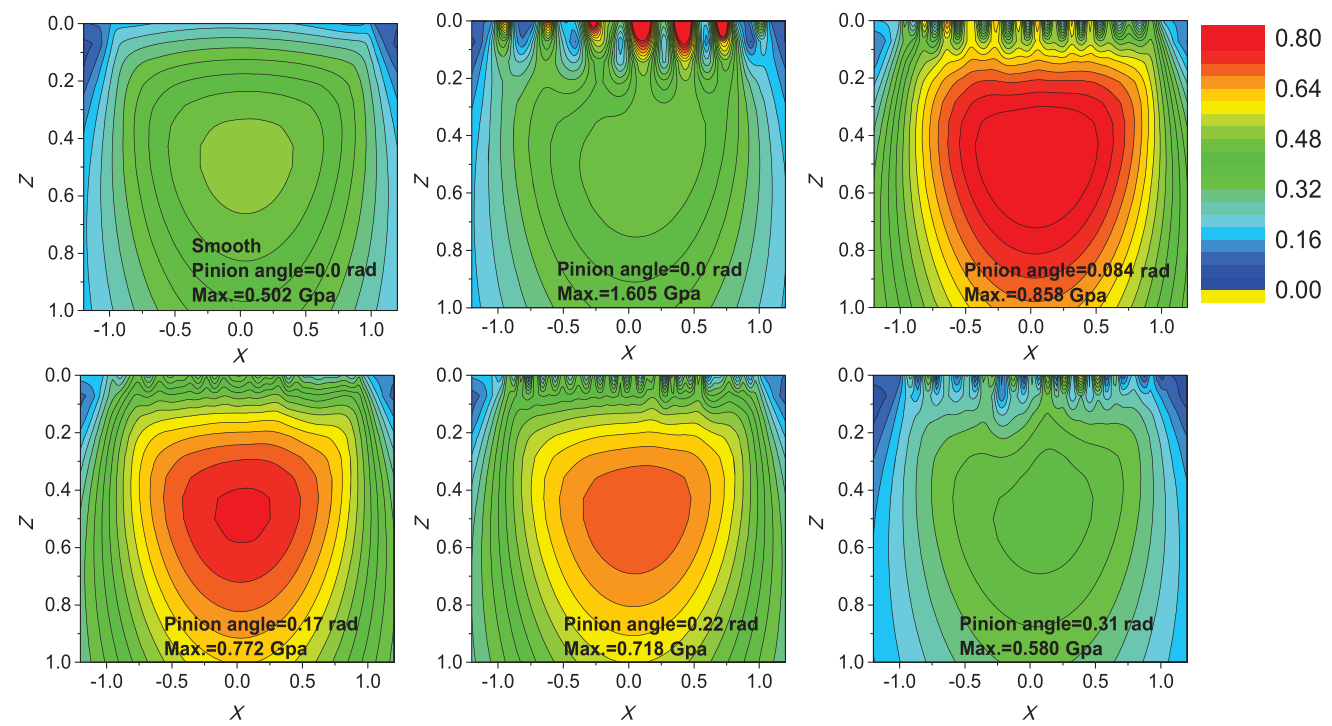

Fig. 12 Subsurface stress distributions at different meshing positions. 
for fatigue life analysis. If the failure probability, Weibull slope $e$, and stress exponent care determined, Eq. (32) can be solved to simulate the fatigue life at the number of cycles $M$ before the fatigue failure. The fatigue life is estimated for a survival probability of $50 \%$ with Weibull slope $e=2.0$ and stress exponent $c=5.0$. Note that the present study focuses on the comparative evaluation of fatigue life under assembling misalignments with the consideration of the stress cycles of asperity contact, and hence, the material parameters are considered irrelevant in this study.

Considering the case of no misalignment, the fatigue life $M$ is investigated for a gear pair during the meshing process with and without asperity stress cycles, and the results are plotted in Fig. 13. If the stress cycle is

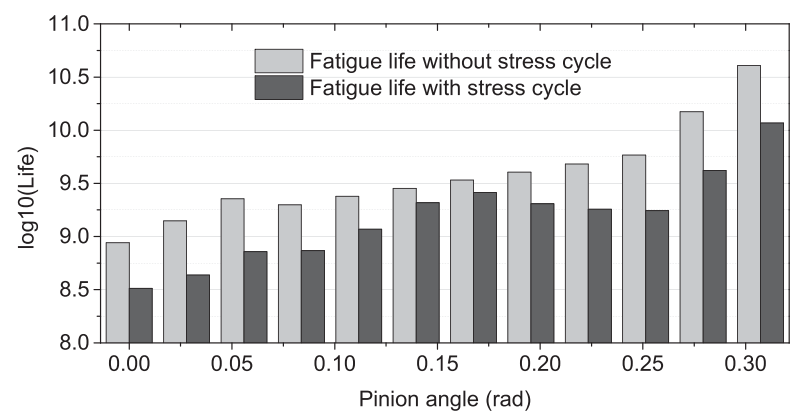

Fig. 13 Fatigue life during the meshing process for the case of no misalignment. not considered, the fatigue life is predicted by Eq. (32) through the integration of stress $\sigma_{e}$ and stressed volume $V$. Note that the stressed volume and high interior stress caused by roughness have been included on right side of Eq. (32). When the microstress cycle is counted, the actual stress cycle becomes $M=N \times n$. Consequently, the asperity stress cycle $n$ would reduce the fatigue life time since $N=1 / n \times M$. As demonstrated in Fig. 13, the fatigue life, without the stress cycle counting, generally increases from the meshing-in point to meshing-out point. It is worth noting that the Hertzian pressure was used as the equivalent stress criteria proposed by Ioannides and Harris [11]. The maximum Hertzian contact pressure at the meshing-in point is lower than that of the pinion angle of 0.028 rad, as shown in Fig. 9, whereas their fatigue lives show a reverse trend. To investigate the mechanism behind this observation, the distributions of octahedral stress at these two points are summarized in Fig. 14. It is observed that higher Hertzian contact pressure leads to larger subsurface stress along $Z$ direction as manifested in Fig. 14(d), whilst the surface stress peaks along $X$ direction of the meshing-in point (pinion angle $=0.0 \mathrm{rad}$ ) caused by asperities are greater than those of the pinion angle of $0.028 \mathrm{rad}$ as shown in Fig. 14(c). It can be concluded that surface stress
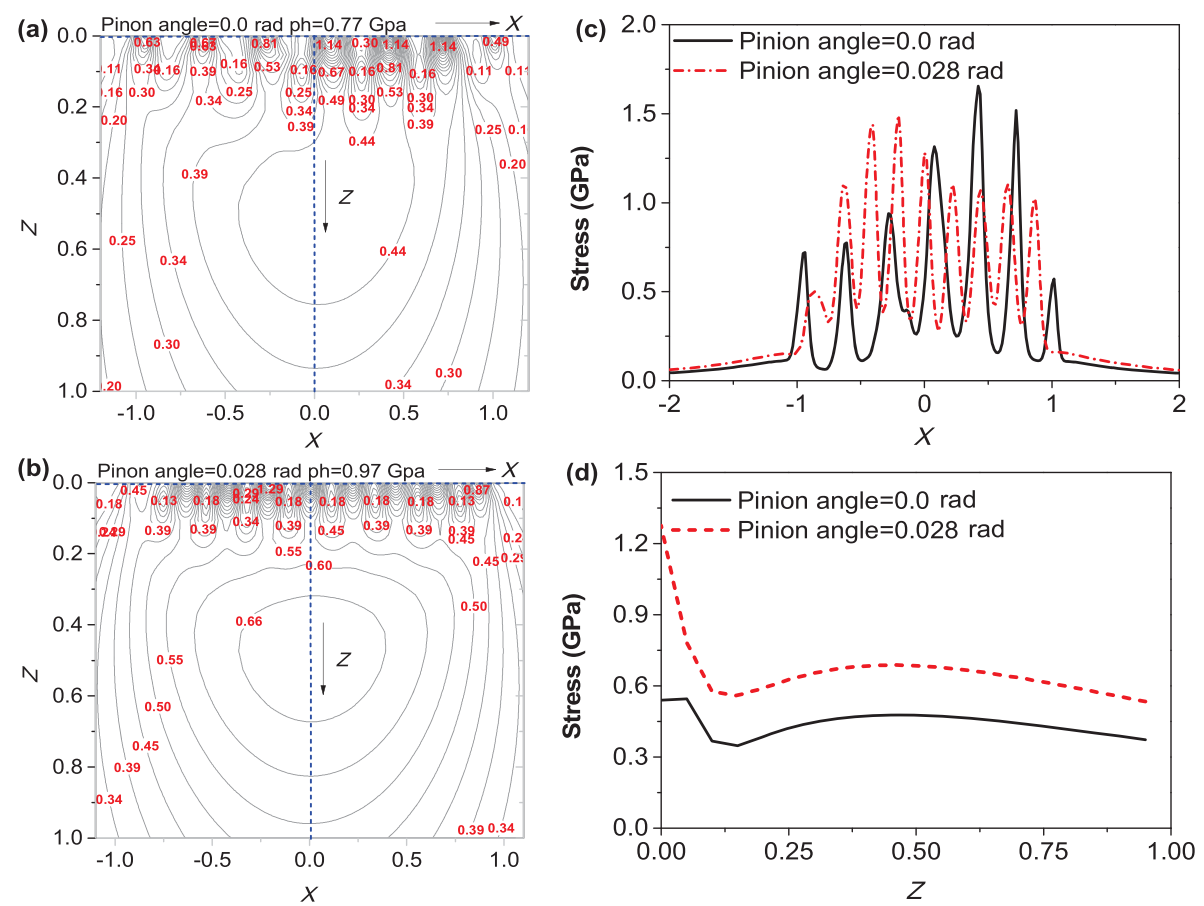

Fig. 14 Octahedral stress at the pinion angle of 0.0 and $0.028 \mathrm{rad}$ (no misalignment). 
concentrations, resulted from asperity contact, have a significant effect on fatigue life, even when the corresponding subsurface stress is relatively small. Hence, under the considerable sliding contact with the rough surface, it seems unreasonable to take the maximum Hertzian contact pressure as the effective stress in the fatigue life model as done in Ref. [11].

The roughness effect on the reduction of fatigue life includes two physical mechanisms, one is the increased stress number due to the sliding motion of asperities, and the other is the high surface stress concentrations resulted from asperity contacts. As summarized in Fig. 13, the asperity contact leads to an obvious reduction in comparison with the case without the asperity stress counting, and the reductions of fatigue and the slide-roll ratio $\left(S R R=2\left|\mathbf{u}_{1}-\mathbf{u}_{2}\right| /\right.$ $\left.\left(\mathbf{u}_{1}+\mathbf{u}_{2}\right)\right)$ are depicted in Fig. 15. According to Eq. (17), the asperity stress cycle is related to the contact geometry (Hertzian contact ellipse) and sliding velocity. Except for the area near the meshing-in and meshingout point, the trend of fatigue life reduction with the pinion angle is the same as that of the $S R R$, which indicates that the sliding velocity is the dominant factor of the fatigue reduction in this meshing range.

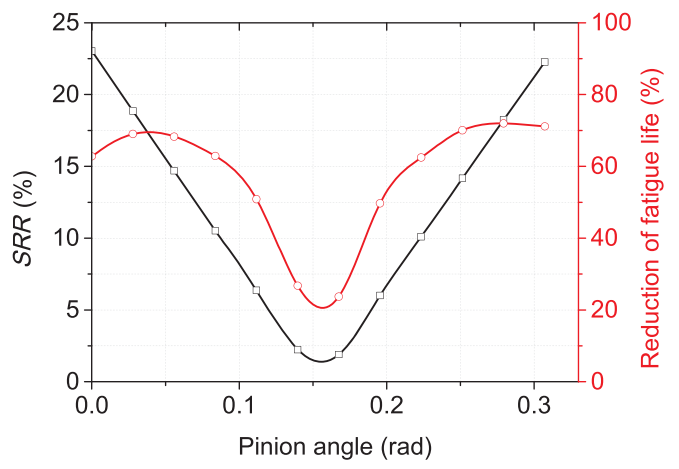

Fig. 15 Variations of $S R R$ and reduction of fatigue life in a mesh cycle.
The surface fatigue failure and bending failure type in spiral bevel gears have been tested experimentally as reported in Refs. [35, 36]; however, there is no available data for the fatigue life in these studies. The experimental investigations on the fatigue life under the rolling-sliding contact can qualitatively support the mechanism of fatigue reduction in spiral bevel gears. Seo et al. [5] measured the fatigue life through two-steel discs experiments, and the results showed that the increase of the $S R R$, from $0.0 \%$ to $0.5 \%$ and $1.5 \%$, caused about 3 and 37 times of increase in the number of pitting occurrences on the contact surface, respectively. Similarly, Rabaso et al. [46] also found that the increase of the SRR from $6 \%$ to $20 \%$ and $40 \%$, resulted in 2.8 and 3.2 times of enlargement in the surface pitting area, respectively. The abrasive wear appeared when the $S R R$ reached $80 \%$, which seemed to remove the pits [46]. Note that the slide-roll ratio for the spiral bevel and hypoid gears are generally less than $50 \%$ in this study and thus, the abrasive wear is not involved in the current fatigue model. The fatigue life reductions of steels under different $S R R s$ were tested by Govindarajan and Gnanamoorthy [47] and Gao et al. [48]. Their experimental results are employed to verify the fatigue predictions (obtained from the present numerical model) in this study, as summarized in Table 4. For items B-1 and B-3, their maximum Hertzian contact pressure, RMS roughness, and $S R R$ are very close to each other, and the fatigue life reduction for items B-1 and B-3 are observed to be $68.95 \%$ and $69.06 \%$, respectively. Items A-2 and A-3 denote the meshing area near the pitch cone line where the SRRS are low (1.89\% and $1.57 \%)$. Their corresponding fatigue life reductions are compared with experimental results in Ref. [47], in which item A-1 generally shows a good agreement. As manifested

Table 4 Qualitative comparison between simulations and available experimental data in literature.

\begin{tabular}{|c|c|c|c|c|c|}
\hline $\begin{array}{c}\text { Item } \\
\text { number }\end{array}$ & Experimental/simulation results & $\begin{array}{c}p_{\mathrm{h}} \\
(\mathrm{GPa})\end{array}$ & $\begin{array}{l}\text { RMS roughness } \\
\qquad(\mu \mathrm{m})\end{array}$ & $\operatorname{SRR}(\%)$ & $\begin{array}{l}\text { Reduction of } \\
\text { fatigue }(\%)\end{array}$ \\
\hline A-1 & Experimental results by Govindarajan and Gnanamoorthy [47] & 1.00 & 0.438 & $0.1 \rightarrow 1.40$ & 24.45 \\
\hline A-2 & Present results, pinion angle 0.17 rad for no misalignment case & 1.05 & 0.55 & $0.0 \rightarrow 1.89$ & 23.71 \\
\hline A-3 & Present results, pinion angle 0.19 rad for Case (c) & 1.17 & 0.55 & $0.0 \rightarrow 1.57$ & 22.39 \\
\hline B-1 & Experimental results by Gao et al. [48] & 1.20 & 0.546 & $0.0 \rightarrow 22.0$ & 68.95 \\
\hline B-2 & Present results, pinion angle $0.0 \mathrm{rad}$ for no misalignment case & 0.77 & 0.55 & $0.0 \rightarrow 23.1$ & 62.77 \\
\hline B-3 & Present results, pinion angle $0.0 \mathrm{rad}$ for Case (d) & 1.17 & 0.55 & $0.0 \rightarrow 22.4$ & 69.06 \\
\hline
\end{tabular}


in Table 4, the numerical fatigue predictions are consistent with the experimental data from previous studies for similar operating conditions.

As shown in Figs. 7-9, the contact load, contact geometry, and sliding velocity, which can affect fatigue life, are different under various assembling misalignments. Figure 16 demonstrates the fatigue life without the asperity stress cycle counting during a meshing cycle, and it can be seen that the fatigue life generally increases from the meshing-in point to meshing-out point. According to Fig. 6, the contact trajectories are different for different cases of assembling errors, i.e., the contact paths under Cases (a) and (d) are shifted to the heel of the gear flank, while the contact paths under Cases (b) and (c) are shifted to the toe of the gear flank, as compared to those of the no

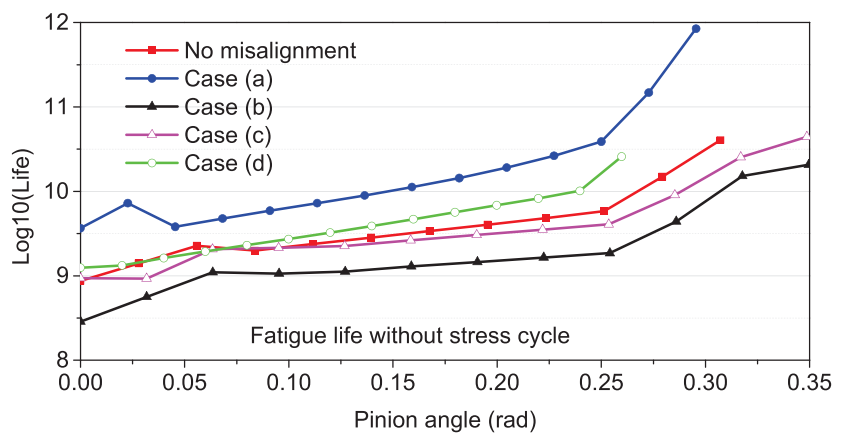

Fig. 16 Fatigue life under different cases of assembling misalignments (without asperity stress cycle counting). misalignment condition. Hence, as revealed in Fig. 16, the contact paths near the toe of the gear flank can reduce the fatigue life. Figure 17 shows the fatigue life with the asperity stress cycle counting, and the trend of the results under various misalignments are similar to that in Fig. 16. As expected, the fatigue life in different cases is considerably decreased owing to the moving asperity stress cycles. In order to explain the difference in the fatigue life under four assembling errors, the octahedral stress distributions at the meshing-in point are plotted in Fig. 18 for Case (a), no misalignment case, and Case (b), which represent three types of contact trajectory. No significant difference is found between the maximum Hertzian contact pressure for these three cases at the meshing-in point, but the maximum octahedral stress peaks are significantly different due

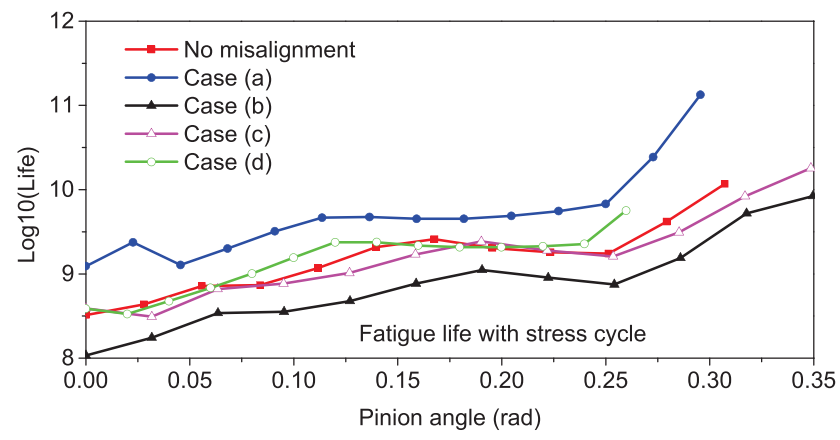

Fig. 17 Fatigue life under different cases of assembling misalignments (with the asperity stress cycle counting).
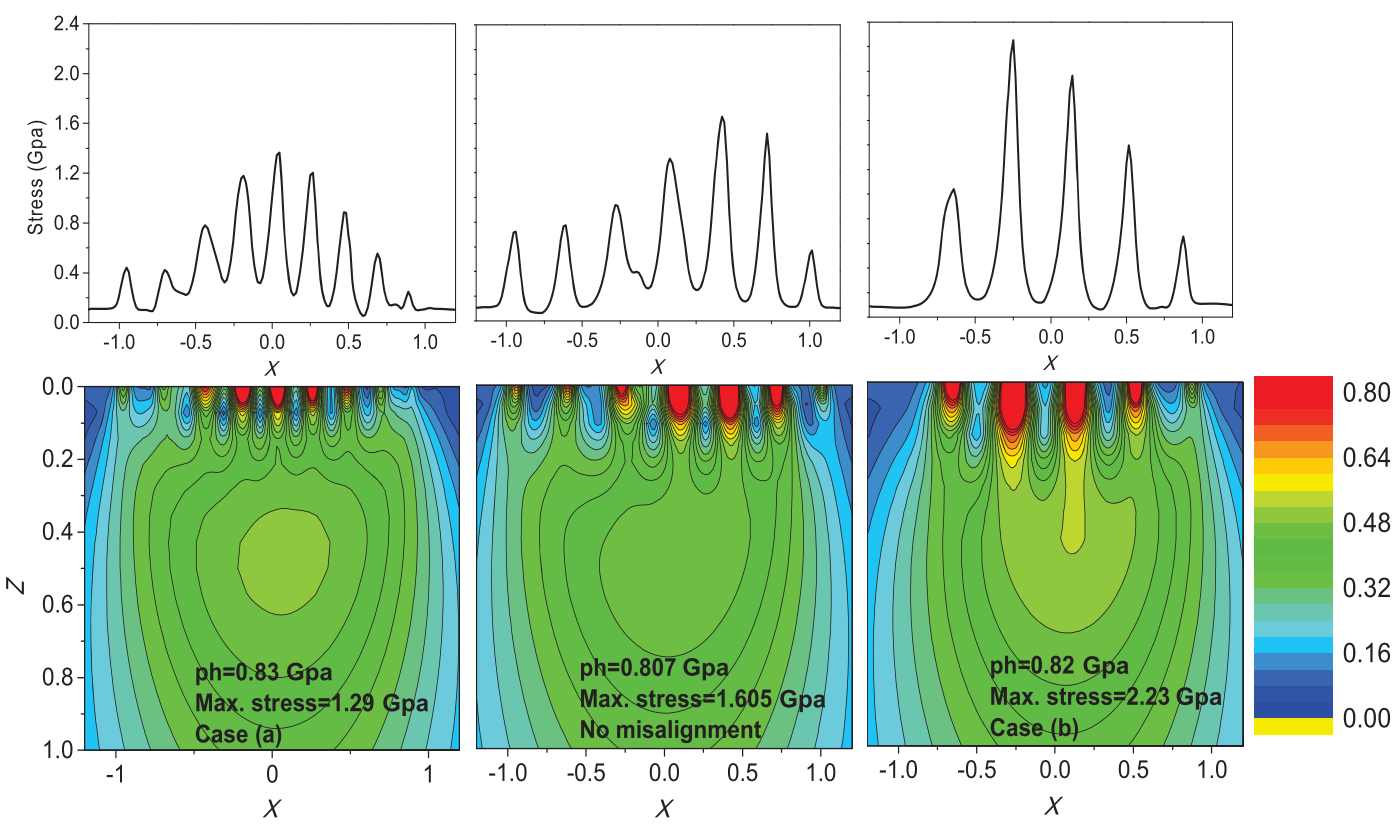

Fig. 18 Octahedral stress at the meshing-in point for Case (a), no misalignment, and Case (b). 
to the variation in the number of asperity contact caused by the change of contact ellipse area. In general, 7, 5, and 9 asperity contact stress peaks are found for Case (a), no misalignment case, and Case (b), respectively. Therefore, as indicated by the contact geometry in Fig. 7, the elliptical contact area is small when the contact trajectory is near the toe of the gear flank, which results in high stress and a significant reduction of fatigue life. Note that long fatigue life is found under the contact path near the heel of the gear flank. However, this does not mean that the contact path should be used as a reasonable trajectory. If the predesigned path is the same with that of Case (a), the edge contact loss or teeth contact loss may occur when the contact path moves further to the heel of the gear flank due to the assembling errors deformations of supporting shaft, which can lead to serious edge damage or impact vibration.

\section{Conclusions}

In this study, a numerical model is established to predict the fatigue life of spiral bevel gears with grinding surfaces. The grinding surface roughness measured by the optical profiler is fitted by sinusoid-like profiles to derive the equation for asperity stress cycle counting, with the consideration of rolling-sliding contact and contact geometry in spiral bevel gears. TCA and mixed EHL model for spiral bevel gears, as developed in previous studies, are applied to obtain pressure, shear stress, and subsurface stress, which are the key parameters for bridging the mixed lubrication analysis with the fatigue life model. The fatigue life is simulated under different assembling misalignments using Zaretsky's fatigue model and asperity stress cycle counting equation.

Simulation results show that the contact pressure peaks decrease during the meshing process and similar trends can also be observed for the corresponding maximum octahedral stresses. Despite the small maximum Herztian contact pressure at the meshing-in point, the roughness asperity causes significant pressure peaks and stress concentrations, showing a significant effect on fatigue life and indicating that using the maximum Hertzian pressure as the effective stress is improper under significant roughness asperity contact. The fatigue life during the meshing process for both with and without asperity stress cycle counting, are compared and the results show that the fatigue life is reduced significantly by the rolling-sliding motion of asperity contact. In addition, based on the qualitative comparison in this study, a good agreement is shown between fatigue life reductions under different contact conditions and available experimental results. Finally, the fatigue life is predicted under various assembling misalignments, and relative low fatigue life is found when the contact trajectory shifts to the toe of the gear flank, due to high stress peaks caused by a small contact curvature radii.

\section{Acknowledgements}

This study is funded by National Science Foundation of China (No. 51875369) and General Projects of Basic Science and Frontier Technology Research of Chongqing (Nos. cstc2016jcyjA0511, cstc2018jcyjAX0451). Wei PU would like to thank Fundamental Research Funds for the Central Universities (No. YJ201752).

Open Access: This article is licensed under a Creative Commons Attribution 4.0 International License, which permits use, sharing, adaptation, distribution and reproduction in any medium or format, as long as you give appropriate credit to the original author(s) and the source, provide a link to the Creative Commons licence, and indicate if changes were made.

The images or other third party material in this article are included in the article's Creative Commons licence, unless indicated otherwise in a credit line to the material. If material is not included in the article's Creative Commons licence and your intended use is not permitted by statutory regulation or exceeds the permitted use, you will need to obtain permission directly from the copyright holder.

To view a copy of this licence, visit http://creativecommons.org/licenses/by/4.0/.

\section{References}

[1] Sadeghi F, Jalalahmadi B. Probabilistic life prediction models for rolling contact fatigue. In Encyclopedia of Tribology. Wang Q J, Chung Y W, Eds. Boston: Springer, 2013. 
[2] Bujold M P, Zhu D, Epstein D, Wang Q, Keer L M. Investigation of sliding/rolling contact fatigue life with both two disk experiments and computer model based prediction. In STLE 2004 Annual Meeting, Toronto, 2004.

[3] Ramalho A, Esteves M, Marta P. Friction and wear behaviour of rolling-sliding steel contacts. Wear 302(1-2): 1468-1480 (2013)

[4] Lee D H, Seo J W, Kwon S J. Numerical analysis of the effect of slip ratio on the fatigue crack initiation life in rolling contact. Adv Mater Res 891-892: 1791-1796 (2014)

[5] Seo J W, Jun H K, Kwon S J, Lee D H. Rolling contact fatigue and wear of two different rail steels under rolling-sliding contact. Int J Fatigue 83: 184-194 (2016)

[6] Oksanen V, Valtonen K, Andersson P, Vaajoki A, Laukkanen A, Holmberg K, Kuokkala V T. Comparison of laboratory rolling-sliding wear tests with in-service wear of nodular cast iron rollers against wire ropes. Wear 340-341: 73-81 (2015)

[7] $\mathrm{Pu} \mathrm{W,} \mathrm{Zhu} \mathrm{D,} \mathrm{Wang} \mathrm{J} \mathrm{X,} \mathrm{Wang} \mathrm{Q} \mathrm{J.} \mathrm{Rolling-sliding} \mathrm{contact}$ fatigue of surfaces with sinusoidal roughness. Int J Fatigue 90: $57-68$ (2016)

[8] Cao W, Pu W, Wang J X, Xiao K. Effect of contact path on the mixed lubrication performance, friction and contact fatigue in spiral bevel gears. Tribol Int 123: 359-371 (2018)

[9] Lundberg G, Palmgren A. Dynamic capacity of rolling bearings. Acta Polytechnica Mech Eng Ser I Roy Swed Acad Eng Sci 1(3): 7 (1947)

[10] Weibull W A. A statistical theory of the strength of materials. Proc Roy Swed Inst Eng Res 151: 5-45 (1939)

[11] Ioannides E, Harris T A. A new fatigue life model for rolling bearings. J Tribol 107(3): 367-377 (1985)

[12] Zaretsky E Y. Fatigue criterion to system design, life, and reliability. J Propul Power 3(1): 76-83 (1987)

[13] Tallian T E. A data-fitted rolling bearing life prediction model-Part I: Mathematical model. Tribol Trans 39(2): 249-258 (1996)

[14] Tripp J H, Ioannides E. Effects of surface roughness on rolling bearing life. In Proceedings of Japan International Tribology Conference, Nagoya, 1990: 797-802.

[15] Ai X L. Effect of three-dimensional random surface roughness on fatigue life of a lubricated contact. J Tribol 120(2): 159-164 (1998)

[16] Epstein D, Yu T H, Wang Q J, Keer L M, Cheng H S, Liu S, Harris S J, Gangopadhyay A. An efficient method of analyzing the effect of roughness on fatigue life in mixed-EHL contact. Tribol Trans 46(2): 273-281 (2003)

[17] Zhu D, Ren N, Wang Q J. Pitting life prediction based on a 3D line contact mixed EHL analysis and subsurface von Mises stress calculation. J Tribol 131(4): 041501 (2009)
[18] Xu G, Sadeghi F. Thermal EHL analysis of circular contacts with measured surface roughness. $J$ Tribol 118(3): 473-482 (1996)

[19] Zhu D, Ai X L. Point contact EHL based on optically measured three-dimensional rough surfaces. J Tribol 119(3): 375-384 (1997)

[20] Jiang X F, Hua D Y, Cheng H S, Ai X L, Lee S C. A mixed elastohydrodynamic lubrication model with asperity contact. J Tribol 121(3): 481-491 (1999)

[21] Shi F H, Salant R F. A mixed soft elastohydrodynamic lubrication model with interasperity cavitation and surface shear deformation. J Tribol 122(1): 308-316 (2000)

[22] $\mathrm{Hu} \mathrm{Y} \mathrm{Z,} \mathrm{Zhu} \mathrm{D.} \mathrm{A} \mathrm{full} \mathrm{numerical} \mathrm{solution} \mathrm{to} \mathrm{the} \mathrm{mixed}$ lubrication in point contacts. $J$ Tribol 122(1): 1-9 (2000)

[23] Holmes M J A, Qiao H, Evans H P, Snidle R W. Surface contact and damage in micro-EHL. Tribol Interface Eng Ser 48: 605-616 (2005)

[24] Bayada G, Martin S, Vázquez C. Micro-roughness effects in (elasto)hydrodynamic lubrication including a mass-flow preserving cavitation model. Tribol Int 39(12): 1707-1718 (2006)

[25] Zhu D. On some aspects of numerical solutions of thin-film and mixed elastohydrodynamic lubrication. Proc Inst Mech Eng, Part J: J Eng Tribol 221(5): 561-579 (2007)

[26] Zhu D, Liu Y C, Wang Q. On the numerical accuracy of rough surface EHL solution. Tribol Trans 57(4): 570-580 (2014)

[27] Greco A, Martini A, Liu Y C, Lin C, Wang Q J. Rolling contact fatigue performance of vibro-mechanical textured surfaces. Tribol Trans 53(4): 610-620 (2010)

[28] Li S, Kahraman A. A fatigue model for contacts under mixed elastohydrodynamic lubrication condition. Int J Fatigue 33(3): 427-436 (2011)

[29] Li S, Anisetti A. A tribo-dynamic contact fatigue model for spur gear pairs. Int J Fatigue 98: 81-91 (2017)

[30] Pu W, Wang J X, Zhang Y, Zhu D. A theoretical analysis of the mixed elastohydrodynamic lubrication in elliptical contacts with an arbitrary entrainment angle. $J$ Tribol 136(4): 041505 (2014)

[31] $\mathrm{Pu} \mathrm{W}$, Wang J X, Zhu D. Friction and flash temperature prediction of mixed lubrication in elliptical contacts with arbitrary velocity vector. Tribol Int 99: 38-46 (2016)

[32] Pu W, Wang J X, Yang R S, Zhu D. Mixed elastohydrodynamic lubrication with three-dimensional machined roughness in spiral bevel and hypoid gears. J Tribol 137(4): 041503 (2015)

[33] Ural A, Heber G, Wawrzynek P A, Ingraffea A R, Lewicki D G, Neto J B C. Three-dimensional, parallel, finite element simulation of fatigue crack growth in a spiral bevel pinion gear. Eng Fract Mech 72(8): 1148-1170 (2005) 
[34] Ural A, Wawrzynek P A, Ingraffea A R, Lewicki D G. Simulating fatigue crack growth in spiral bevel gears using computational fracture mechanics. In ASME 2003 International Design Engineering Technical Conferences and Computers and Information in Engineering Conference, Chicago, 2003: 195-199.

[35] Asi O. Experimental surface contact fatigue failure analysis of a hypoid pinion used in differential system of a truck. Int J Heavy Vehicle Syst 18(1): 104-114 (2011)

[36] Xi L, Wang S W. Experimental investigation of bending fatigue life of driving pinion tooth of hypoid bevels. J Test Eval 44(6): 20140378 (2016)

[37] Goldfarb V, Barmina N. Theory and Practice of Gearing and Transmissions: In Honor of Professor Faydor L. Litvin. Cham (Germany): Springer, 2016.

[38] Álvarez Á, Calleja A, Arizmendi M, González H, de Lacalle L N L. Spiral bevel gears face roughness prediction produced by CNC end milling centers. Materials 11(8): 1301 (2018)

[39] Litvin F L, Fuentes A, Hayasaka K. Design, manufacture, stress analysis, and experimental tests of low-noise high endurance spiral bevel gears. Mech Machine Theory 41(1): 83-118 (2006)

[40] Fan Q. Enhanced algorithms of contact simulation for hypoid gear drives produced by face-milling and face-hobbing processes. J Mech Des 129(1): 31-37 (2007)

[41] Cheng W, Cheng H S, Keer L M. Experimental investigation

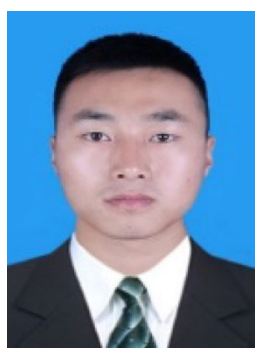

Wei CAO. He received his Ph.D. degree in mechanical engineering from Sichuan University, China, in 2019. Now, he is a lecturer at School

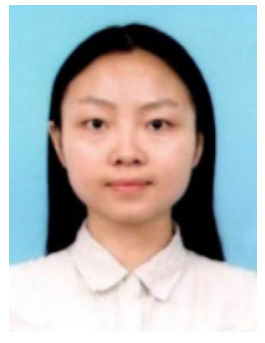

Si REN. She received her bachelor degree in electronics and information engineering from Sichuan University, China, in 2015. Now, she is a doctoral student in School of on rolling/sliding contact fatigue crack initiation with artificial defects. Tribol Trans 37(1): 1-12 (1994)

[42] Wang Y Z, Chen Y Y, Zhou G M, Lv Q J, Zhang Z Z, Tang W, Liu Y. Roughness model for tooth surfaces of spiral bevel gears under grinding. Mech Machine Theory 104: 17-30 (2016)

[43] Zhu D, Cheng H S. An analysis and computational procedure for EHL film thickness, friction and flash temperature in line and point contacts. Tribol Trans 32(3): 364-370 (1989)

[44] Bair S, Winer W O. A rheological model for elastohydrodynamic contacts based on primary laboratory data. J Lub Tech 101(3): 258-264 (1979)

[45] Johnson K L. Contact Mechanics. Cambridge (UK): Cambridge University Press, 1985.

[46] Rabaso P, Gauthier T, Diaby M, Ville F. Rolling contact fatigue: Experimental study of the influence of sliding, load, and material properties on the resistance to micropitting of steel discs. Tribol Trans 56(2): 203-214 (2013)

[47] Govindarajan N, Gnanamoorthy R. Rolling/sliding contact fatigue life prediction of sintered and hardened steels. Wear 262(1-2): 70-78 (2007)

[48] Gao C K, Qi X M, Snidle R W, Evans H P. Effect of film thickness ratio on gearing contact fatigue life. In IUTAM Symposium on Elastohydrodynamics and Microelastohydrodynamics. Snidle R W, Evans H P, Eds. Dordrecht: Springer, 2006: 423-434.

of Construction Machinery, Chang'an University, China. His research interests are tribology, dynamics, and fatigue in transmission systems.

Aeronautics and Astronautics at Sichuan University, China. Her research work covers the tribology of planetary gear and bevel gear. 


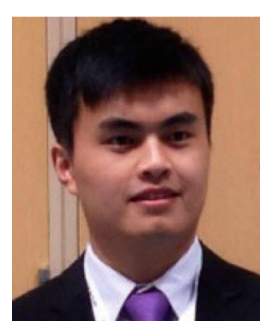

Wei PU. He received his Ph.D. degree in mechanical engineering from Sichuan University, China, in 2017. He currently is an associate research fellow at School of Aeronautics and

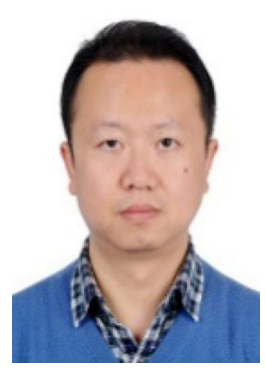

Ke XIAO. He received his Ph.D. degree in mechanical engineering from Chongqing University, China, in 2012. He is an associate research
Astronautics, Sichuan University, China and a visiting scholar in Massachusetts Institute of Technology, USA. His interests include the lubrication and friction in transmission components. fellow at College of Mechanical Engineering, Chongqing University, China. His research interests are the nonlinear dynamic of flexible drive mechanism and system. 